\title{
Hybridity is Dead. Long Live Hybridity!
}

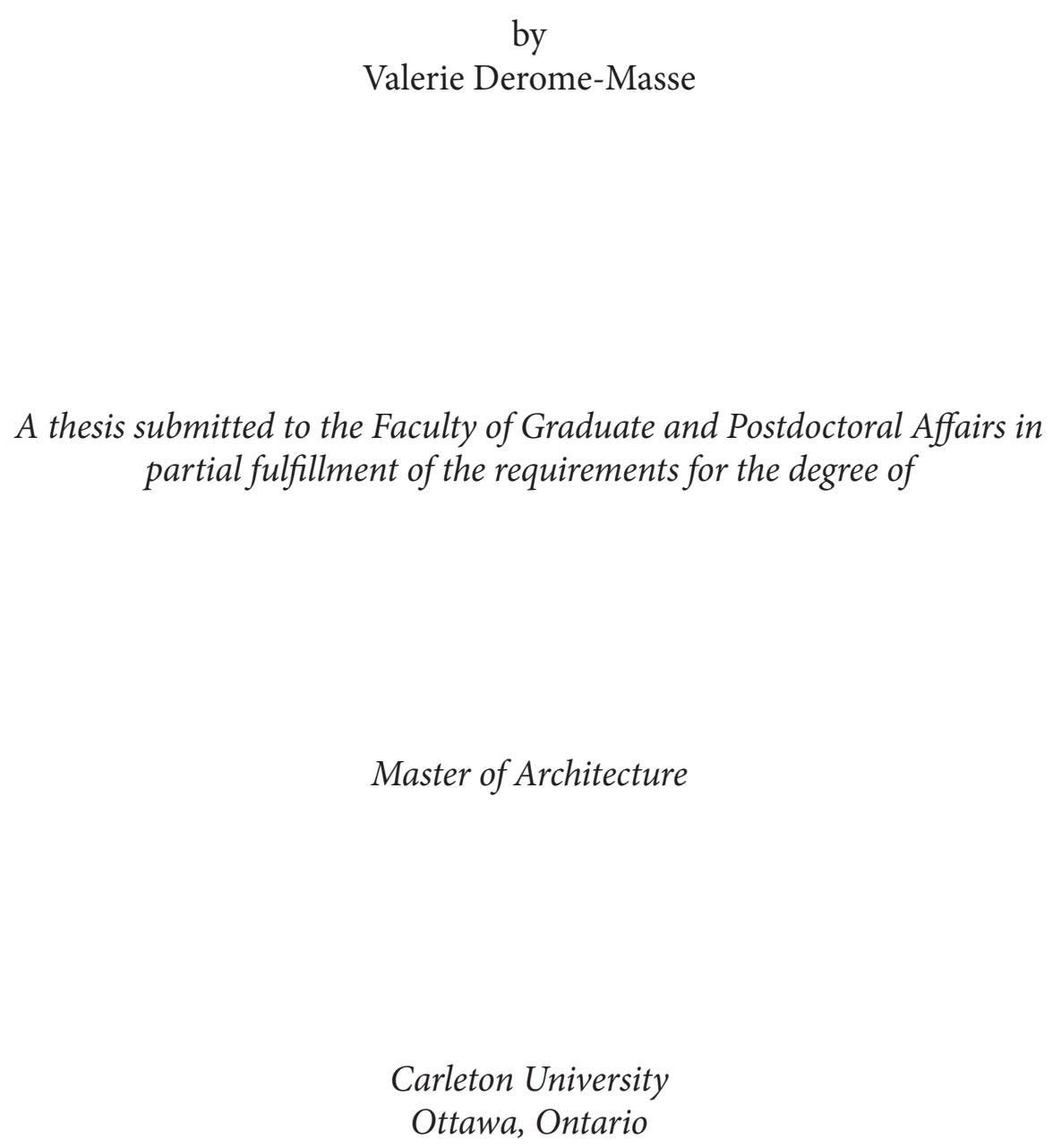

(C) 2015

Valerie Derome-Masse 


\section{Abstract}

In present cities, escalating land values and the growing pressure on developers to optimize the utilization of built areas are changing the way architects engage with projects in urban environments. Architectural ideas are now more likely to be driven by density, diversity and intensity of uses in order to revitalise urban centers.

Some of the forms and ideas put forward by the Modern Movement failed to deal with urban engagement by imposing a segregation and rationalization of architecture which resulted in the alleged death of cities towards the end of the 20th century. The notion of hybridity has been blamed for the decline of Modernism and has been held responsible for some of its extremes.

Hybrid architecture focuses on contemporary concerns by marrying multiple ideas under a single infrastructure which highlights a diversity of living experiences, programs and people. The hybrid building looks for an unexpected mix of activities that intensify its usage as well as amalgamate the diversity of the surrounding urban fabric. Hence, the alliance generated between private and public spheres as well as the linking between disparate programs can produce new situations that stimulate and revitalize buildings and their environment.

This research promotes a re-assessment of hybrid architecture using an analysis of several projects with distinctive program combinations adapted to several site conditions. The thesis then proceeds to explore the potential, and re-emergence, of hybrid architecture to create invigorating synergies between programs. Bylooking beyond the hybrid, the thesis project will seek hybridisation through interchangeable architectural spaces. Hybridity is dead. Long live hybridity! 


\section{Acknowledgements}

Many thanks go to my thesis advisor Roger Connah for his constant support and help for the fulfillment of this thesis. Thank you to Professor Johan Voordouw for his thoughtful advice and enthusiasm for this topic.

I am also thankful to my family who supported me throughout my master's degree and my parents who, as role models, influenced me in always believing in my dreams.

Lastly, thank you to all the inspiring people I met at Carleton University, especially Thaly, an exceptional school partner with who I share unforgettable memories of our journey at the architecture school. 


\title{
Table of contents
}

Abstract 2

Acknowledgements 3

Table of contents 4

Glossary 5

Prologue: From Hybridisation to Hybrid Architecture

Etymology 9

A debatable topic 10

Hybrid vs. Mixed-use 13

Developing Hybrid Architectures 15

\section{Part one: Hybridity is Dead.}

The Fragmented City 25

Modern Diagrams 26

The Skycraper Fantasy 29

\section{Part two: Long Live Hybridity!}

From Hybrid Architecture to the City 32

\section{Part three: Beyond the Hybrid}

Interchangeable spaces 46

Urban sponge 47

\section{Post-script}

Hybrid Really? 59

\author{
Endnotes 62 \\ List of figures 69 \\ Bibliography 73
}




\section{Glossary}

\section{Alliance (n):}

A union or association formed for mutual benefit. The state of being joined or associated. ${ }^{1}$

\section{Assemblage (n):}

Be or come together. A group of things found together in a closed context or association. ${ }^{2}$

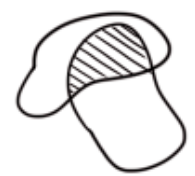

Figure 1.

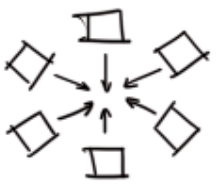

Figure 2.

\section{Blending (v):}

Mix (a substance) with another substance so that they combine together. ${ }^{3}$

\section{Blend (in/into) (n):}

Be an unobtrusive or harmonious part of a greater whole by being similar in appearance or behaviour. ${ }^{4}$

\section{Community (n):}

The quality of holding something in common, as in a community of interests, community of goods. ${ }^{5}$

\section{Crossprogramming (v):}

Using a given spatial configuration for a program not intended for it. Displacement and mutual contamination of terms. ${ }^{6}$

\section{Diagram (n):}

The Japanese architect Toyo Ito defines the diagram as an analytic and operational device. It is used as a tool to reduce vast amount of data to a few schematic representations. The use of the diagram is present during the process of design to clarify and justify certain decisions. For Toyo Ito, diagrams are ideal instruments for depicting a codex of rules that applied to a building. ${ }^{7}$ 
Fragmentation (n):

The process or state of breaking or being broken into fragments. ${ }^{8}$

Figure 3.

\section{Hybrid (n):}

A thing made by combining two different elements. Of mixed character; composed of different elements. ${ }^{9}$ In biology, the process of hybridization increases the genetic variety (number of different gene combinations) within a species, which is necessary for evolution to occur. If climatic or habitat conditions change, individuals with certain combinations may be eliminated, but others with different combinations will survive. In this way, the appearance or behaviour of a species gradually may be altered. Such natural hybridization, which is widespread among certain species, makes the identification and enumeration of species very difficult. ${ }^{10}$ Hybrid can also relate to crosses between populations, breeds or cultivars of a single species. ${ }^{11}$

\section{Hybridity (n):}

For Homi K. Bhabha, it represents a condition between states whose virtue it that it escapes the control of either. As such, it has considerable subversive potential. Bhabha celebrates the in-between spaces created and inhabited by hybrids, and holds that all cultures are now caught up in a continuous process of hybridization. ${ }^{12}$

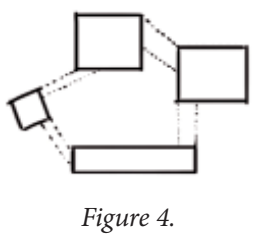

\section{Hyperbuilding (n):}

To Rem Koolhaas, the Hyperbuilding can be read as the integration of several buildings into a larger whole. ${ }^{13}$

\section{Interaction (n):}

Reciprocal action or influence. ${ }^{14}$ 


\section{Interdependence (n):}

The dependence of two or more people or things on each other. $^{15}$

\section{Mutation (n):}

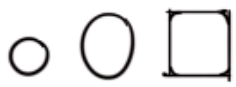

Figure 5.

The act or process of being altered or changed. An alteration or change, as in nature, form, or quality. ${ }^{16}$

Organism (n):

A system or organization consisting of interdependent parts, compared to a living being. ${ }^{17}$

\section{Permutation (n):}

A determinate set of expected occurrences, a list of required utilities, often based on social behavior, habit or custom. ${ }^{18}$

\section{Program (n):}

A determinate set of expected occurrences, a list of required utilities, often based on social behavior, habit or custom. ${ }^{19}$

\section{Synergy (n):}

The additional benefit accruing to a number of systems should they coalesce to form a larger system. The creation of a whole that is greater than the simple sum of its parts. ${ }^{20}$

\section{Segregation (n):}

The action or state of setting someone or something apart from others. ${ }^{21}$

\section{Transprogramming (v):}

Combining two programs, regardless of their incompatibilities, together with their respective spatial configurations. ${ }^{22}$ 


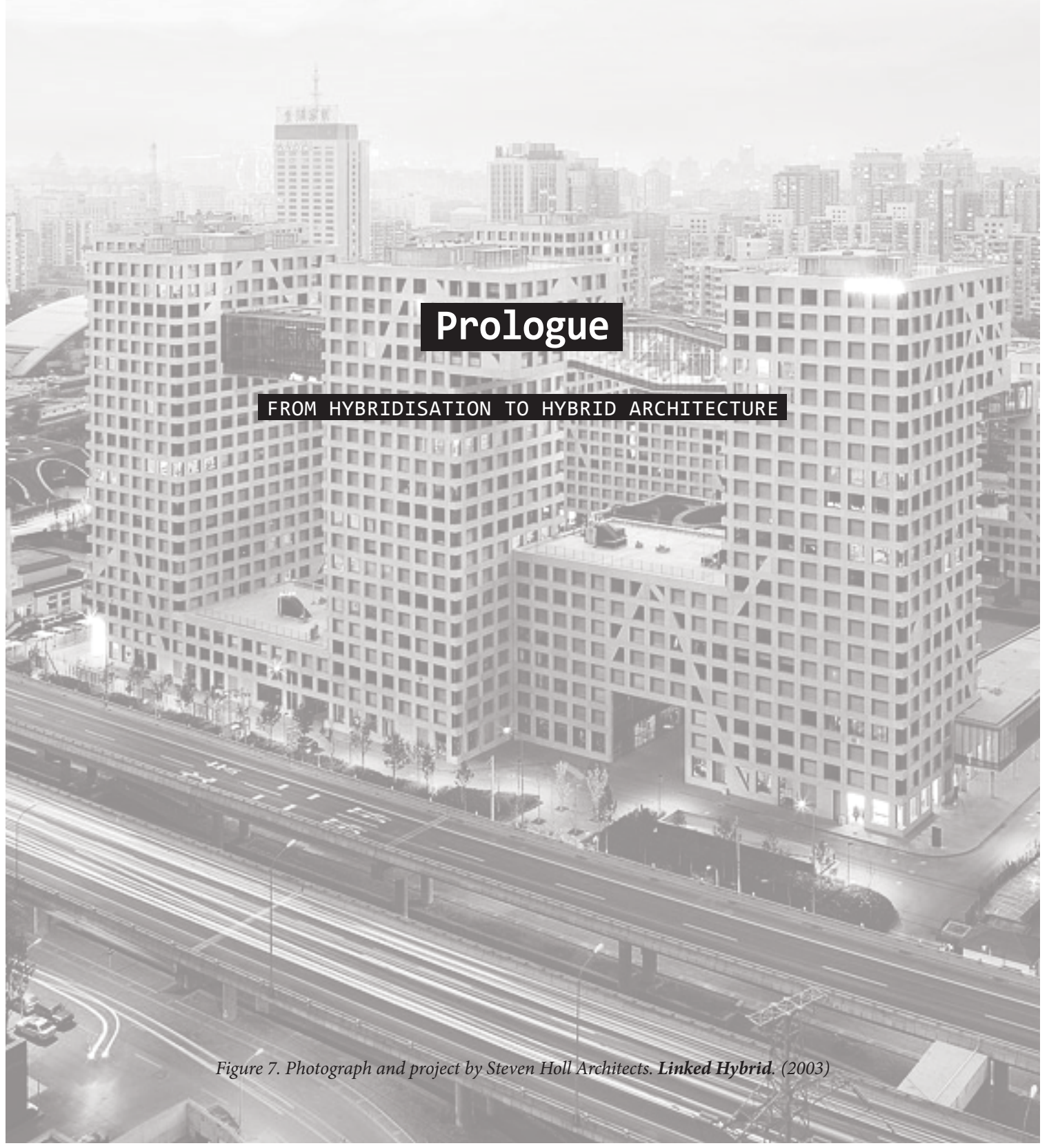




\section{Etymology}

FROM HYBRIDISATION TO HYBRID ARCHITECTURE

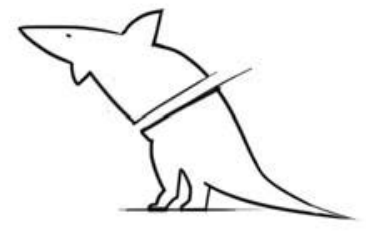

Figure 8.
Hybridity is a relatively new concept recognized by science between the 18th and 19th century defined by Alan Bullock and Stephen Trombley as "a thing of mixed character or composed of different elements." ${ }^{23}$ Being the result of collisions between similar and/or dissimilar elements, regardless its field of study, hybridization aims the creation of a new kind.

In the contemporary world of now, the hybrid is most commonly known as a technological advancement in the automobile industry where the merging of two distinct power sources creates a new type of vehicle. The hybrid vehicle has both an electric motor and an internal combustion engine which are united to give power either individually or together. But, hybridization as a genetic concept is a term commonly used in biology again by Bullock and Tremblay to define "the breeding together of two species" ${ }^{\prime 24}$ which made possible the origin of certain animal species. In botany for instance, many plant species are artificially made by merging different species together. Hybridization was invented as a way of creating new genetic combinations better adapted to changing or disturbed habitats.

Similarly, humans are now evolving in a disrupted environment which appears to bear the weight of previous design mishaps. 
In this sense, hybridization can be seen to represent a viable tendency in relation to urban and architectural studies. It is often considered that Post-modernism, clearly a tendency identified after Modernism from the 1970s into the 1980s, brought a vision of architecture that was according to the research group $a+t$, a "resurgence of interest in testing program and challenging predominant typological models." ${ }^{25}$ The understood failure of Modern planning encouraged the growth of architectures from the homogenous to the heterogeneous with respect to use. Architects of the present era are pushing towards coexistence of various uses through dialectic concepts in which unexpected programs are combined.

For the purpose of this thesis, the term hybrid is used cautiously with respect to its broader meaning and refers to an innovative aspect suitable to describe various contemporary forms. This thesis will therefore employ a terminology that has been rarely used in the past twenty years, even as far back to when Bernard Tschumi ${ }^{26}$ introduced trans-programming to architecture.

\section{A Debatable Topic}

FROM HYBRIDISATION TO HYBRID ARCHITECTURE

As a crucial notion of our time, this trend of blending proposes associations of ideas and/or concepts reinforcing each other. Rather than proposing an individual concept or idea, hybridity is seen as generating a new strength through the merging of complementary or dissimilar elements. 
Thus, divergent elements may be combined to create unprecedented concepts in this case as an attempt to vitalize the city.

* Peter Block. A Sense of Belonging. Kinfolk 18. (2015) p. 51

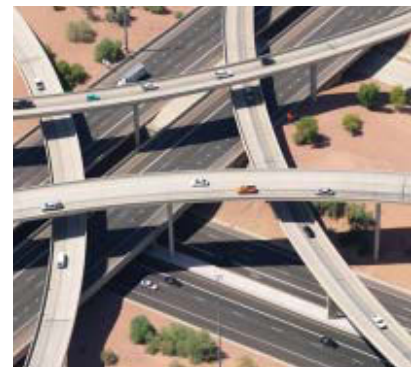

Figure 9.

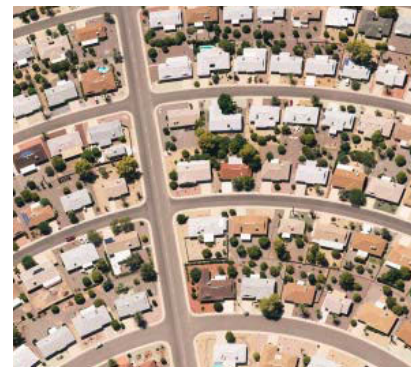

Figure 10. Photograph of Arrowhead Lakes, Arizona by Justin Fantl. Kinfolk 18. (2015)

\section{It is this dividedness that makes it so difficult to create a more positive or alternative future, especially in a culture that's much more interested in individuality and independence than interdependence.*}

Growing in an accepted age of isolation, American cities have been broken apart due to the confinement or what is referred to in Western culture as "our individualistic narrative, the inward attention of our institutions and our professions and the messages from our media [that] all fragment us." ${ }^{27}$ We may be evolving in a technological era that progresses extremely quickly and provides us with "instant sharing of information, quick technology [and] workplaces that operate around the globe," 28 but it also appears to be the cause of our seclusion.

The fragmented fabric which characterizes most of North American cities today contributes greatly to the making of individualized and self-interested individuals and deregulated systems and societies. Our communities are made up of collections of "institutions and programs operating near one another but not overlapping or touching." ${ }^{29}$ 


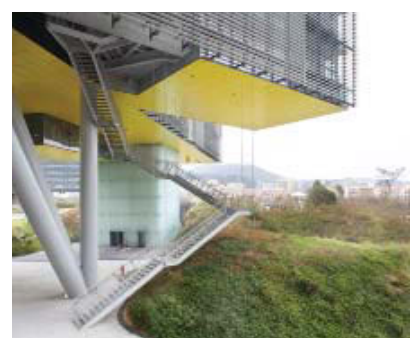

Figure 11 .

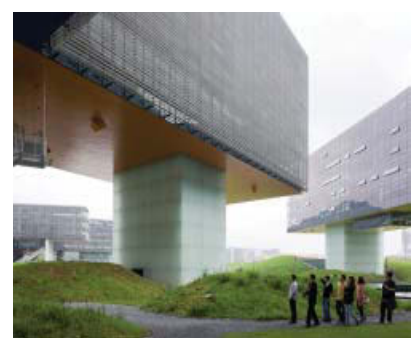

Figure 12. Photograph and image by Steven Holl Architects. Vanke Center. (2006)
Hybrid architecture appears then to reintroduce interdependence in design strategies in order to overcome the prevailing fragmentation and individualism. Architects may benefit from the freedom allowed by the hybridization of architecture and favour various combinations of functions so as to create "single entities constantly changing and evolving as one." ${ }^{30}$ Recent approaches have created a growing interest in programs in buildings opening up opportunities for architects to innovate and challenge architectural forms.

Whereas hybridization may represent an attempt to invigorate the city, it still represents a controversial process that raises questions in regard to its meaning and contribution to architecture. Because its value is easily questionable, many theorists and architects have been arguing over its significance and usefulness. Hybrid architecture was highly contested in the mid-20th century and still represents today a debatable topic. It features an often misused terminology and thus, we must pose the question whether hybrid architecture can, to this day, be defined or not.

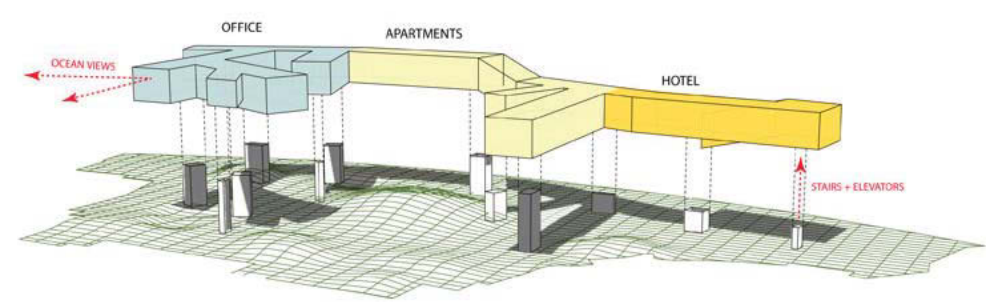

Figure 13. 


\section{Hybrid vs mixed-use}

FROM HYBRIDISATION TO HYBRID ARCHITECTURE
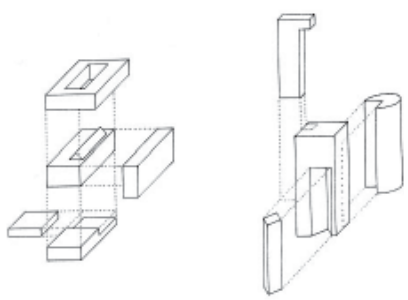

Figure 14. Drawing by Joseph Fenton. Pamphlet Architecture: Hybrid Buildings. Architectural Books.(1985)
From biological science to building science, hybridization seems to be fuelled by progress and innovation. The alleged freedom of invention allowed by hybrid architecture profits from the merging of concepts and creates unprecedented building typologies. According to the architect Joseph Fenton, buildings have also been "crossed like plants and animals to produce hybrid architecture." ${ }^{31}$ Making the most out of its multiple abilities, the hybrid building aims to revitalise the urban scene and also save space. New typologies may emerge from trans-programming to create buildings that are much more responsive to their context and sensitive of their own behaviour. But how much can we accept of this notion of responsiveness?

The "crossed fertilisation environments" 32 in hybrid architecture where "new genetic alliances are created"33 is often mistaken for mixed-use buildings. Essentially, both typologies share the same approach: the mixing of programs under a single roof. However, the hybrid building appears to feature indeterminacy and synergies between its functions so as to encourage the mixing of knowledge and other forces.

Hybrid architecture finds its meaning through diversity and a unique alliance between activities. In a likely manner, mixed-use buildings hold a certain degree of diversity because of the variety of functions they contain. 
But unlike hybrids, mixed-use buildings, according to Jane Jacobs, do not rely on "an array of identities, unpredictable vectors of connection and uncontrollable contagions" ${ }^{\prime \prime 4}$ to enhance the presence of synergies within their envelopes. There is indeed no interdependence between functions and the building does not seem to rely on diversity to create constructive forces.

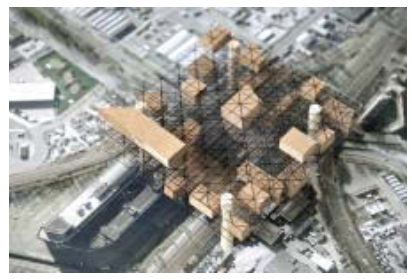

Figure 15.

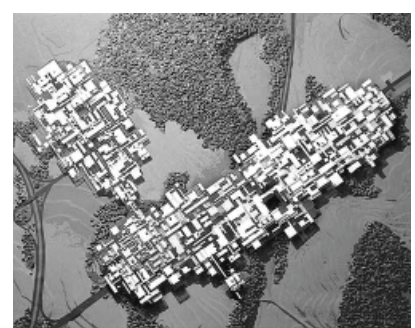

Figure 16. Drawing by Yona Friedman. Ville Spatiale. (1959)
However, to Yona Friedman, this mutability of programs relies on functions which "are not separated on a physical level, but on an ideas level"35 rather than being exclusively separated through the stacking of floors. Hybridization seems to generate dialogues favoring a dynamic spatial indeterminacy of events. Similarly, the research group a+t points out that this interrelationship of uses "in a hybrid building generates a potential which is transferred, as in a system of connected vessels, to those weaker activities so that all involved are benefited." ${ }^{36}$ In hybrid architecture, the strength of some programs can be transferred to others in the same entity such that the whole building despite its various activities works as one organism.

Eventually, as hybrid buildings encourage the meeting of private and public domains, they can become instruments of urban regeneration. Responding directly to contemporary urban concerns such as land scarcity and part-time ghost neighborhoods, the concentration of various activities under one roof promotes the creation of "buildings working full-time." ${ }^{37}$ The hybridization process can go beyond the process of building for maximum density and profits from the alliances between activities to maintain a constant animation within its envelope. 
Unlike the mixed-use building whose trans-programmation relates simply on density, the hybrid building appears to exist exclusively through the simultaneous presence of three prominent ingredients: intensity, diversity and density.

\title{
Developing Hybrid Architectures
}

\author{
FROM HYBRIDISATION TO HYBRID ARCHITECTURE
}

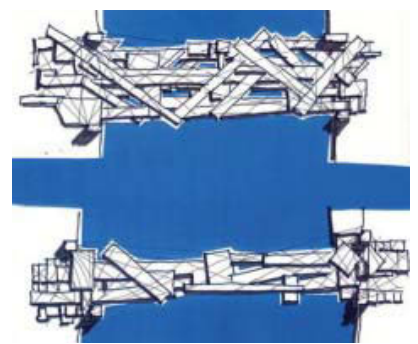

Figure 17. Drawing by Yona Friedman. Shanghai Bridge. (2009)

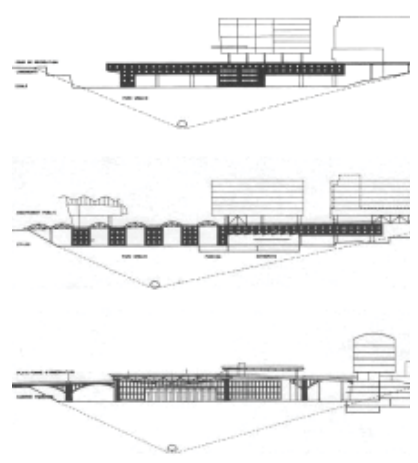

Figure 18. Drawing by Bernard Tschumi. Project Bridge-City, Lausanne.(1988)
Hybridity has existed in architecture in many forms throughout history and has evolved through different organisations and across a number of scales from the microprogrammatic level all the way up to the urban scale. The premise of hybrid architecture dates back from the Roman Empire when projects such as the Ponte Vecchio and the Roman Baths incorporated more than one function within their infrastructures.

More recently, an analysis of inhabited bridges as a hybrid solution was undertaken by the deconstructivist architect Bernard Tschumi. The project initiated in 1988 takes advantage of Lausanne's existing bridge typology by extending its geometry to create new density and spatial relationships between uses. Using dynamic movements and programs, Tschumi develops a new concept of urban combination through the merging of past and present. Five bridges become "circuits of movement" 38 and feature unpredictable programmatic factors for the revitalisation of an existing urban area. 
* Bernard Tschumi. Event-cities (praxis). The MIT Press. (1994) p.157

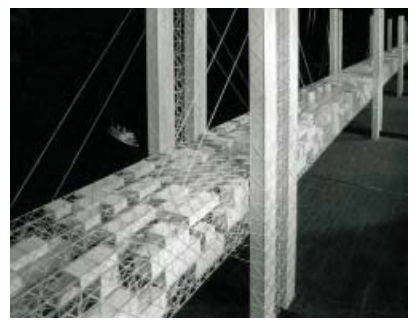

Figure 19. Drawing and model by Yona Friedman. Shanghai Bridge Project. (2009)

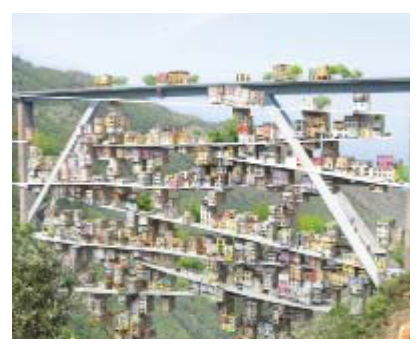

Figure 20. Image by Ja Architecture Studio Inc. Solar Park South. Online: jastudioinc.com

\section{The concept of the urban generator} not only allows new spatial links with the existing city but encourages unpredictable programmatic factors, new urban events that will inevitably appear in coming decades.*

The same question applies today: whether inhabited bridges may become more than agents of connectivity and engage with the urban fabric? If we follow Tschumi, applying distinct programs to existing bridges allows them to stand out with their own character and thus bring back to life a certain area. The living bridge has been forgotten for a long period of time and seems to respond to contemporary urban concerns related to density and diversity. The inclusion of various activities on the bridge itself mimics the intensity of the city and allows it to become a destination rather than simply a passage way. Is this still relevant today?

Inhabited bridges profit from the immensity of scale to instigate a "regime of complexity." ${ }^{39}$ This ensures a constant density and intensifies the usage of an area. Its versatility is also a key feature which relates to hybrid architecture as it has the capacity to bond to the existing infrastructures and facilitate the dialogue with the urban fabric. But beyond the regeneration it produces, whether it is an addition to an existing infrastructure or a whole new entity, the inhabited bridge appears to produce true urban events responding to the desired revitalization of cities. 


\section{The "Bigness" Syndrome (1990s)}

Can we however accept that hybrid architecture does not relate to a specific typology as it has the capacity to create infinite new typologies? Trans-programming is often related to a certain form of grandeur as it may engage many programs within one typology. Hybridity seems to dialogue easily with other urban landmarks as it often features a scale that stands out in the urban scheme.

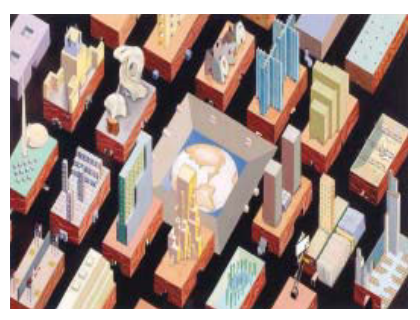

Figure 21. Drawing by Rem Koolhaas. Delirious New York. The Monacelli Press. (1997)
Between 1900 and 1910 in American cities, hybrid architecture emerged along with the rise of the skyscraper. According to Fenton, as horizontal movements were restricted, "the city fabric moved skyward." ${ }^{40}$ Technological advancements such as structural framing and the invention of the elevator encouraged the stacking of floors and the race for the highest building. This generation of conceptual breakthroughs was triggered partly because of emerging technologies and produced what Rem Koolhaas prescribed as an "architectural Big Bang."

In addition to the evolving technologies favouring the development of skyscrapers, the economic context of the 19th century incentivised developers to "maximise volume and floor area to make the most of valuable real estate." ${ }^{42}$ As developers were unable to allocate a single use to these vast spaces, functions were inevitably combined. Rather than isolating programs in different parts of the city, the skyscraper became the single entity in which various combinations of programs could co-exist on separate floors. 


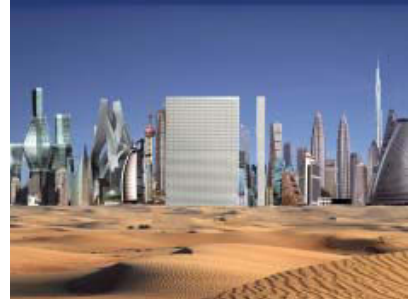

Figure 22.

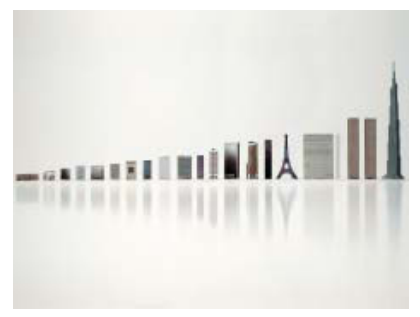

Figure 23. Image by OMA. Dubai Renaissance. (2006)

${ }^{*}$ Rem Koolhaas. S, M, L, XL. (1997)
p. 512
This allowed programs such as dwellings, offices, museums, factories, theaters to often be stacked one above the other. This might also be interpreted as richer programming and, consequently, a precursor to hybridization.

In response to the constraints of the city grid, the stacking of floors often with little spatial relation to one another found in such "sprawling megastructures (Fenton)" 43 sees the elevator as the only unifying element; each level according to Koolhaas is "treated as a virgin site" 44 as if the others did not exist. Hence, the horizontal movement is replaced by vertical movement inside buildings so as to decongest the surface of the earth while supporting the underlying gridded urban pattern. Apart from this increasing urban density, another factor was driving the mixing of programs in architecture: gigantism.

\section{The world is decomposed into incompatible fractals of uniqueness, each a pretext for further disintegration of the whole.*}

To Rem Koolhaas, gigantism, also defined as bigness, was "one of Manhattanism's most insistent themes"45 which made New York a metropolis made up of "a collection of architectural city-states all potentially at war with each other." ${ }^{36}$ Bigness indeed created a collection of introverted creatures which were fuelled initially by the "thoughtless energy of the purely quantitive." 47 
${ }^{*}$ Rem Koolhaas. Delirious New York. Monacelli Press. (1997) p. 177

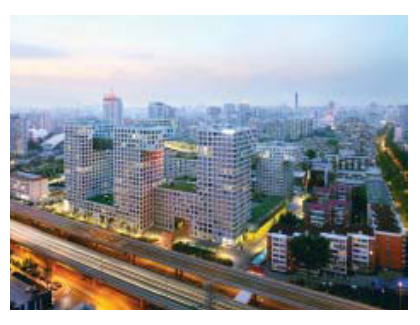

Figure 24.

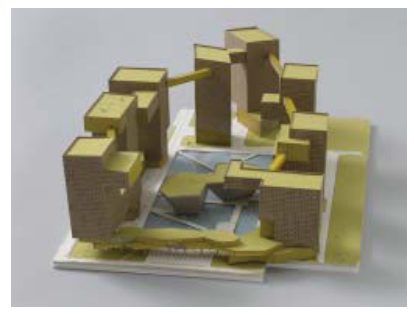

Figure 25. Image from Museum of Modern Art, New York. Project by Steven Holl. Linked Hybrid. (2003)
Gigantism stormed Manhattan and buildings indeed became taller and bigger than ever before. As it was the case for the Babel tower, the hyper-architecture produced by bigness focused entirely on scale.

\section{Manhattan is now a quiet metropolitan plain marked by self-contained universes of mountains $(. .) .$.}

Over the last 20 years, a critical "boom in high density buildings has in part been fed by exploding economies, astronomical rises in land value and the rise of emerging economic zones" 48 particularly in China. Over a period of only 10 years, cities such as Shenzhen and Beijing have seen their population expand radically. A hyper-urbanization has been observed in those cities in particular and has acted as fertilizers for the growth of hybrid architecture.

Responding to a major population increase, architects such as Steven Holl developed projects that simultaneously create high-density projects and contributed to public space formation in the heart of city centres. It appears that hybrid buildings can create stimulating and active new public spaces. The conditions which seemed to have favored the evolution of hybrid architecture enabled a renegotiation with the formation of public space in relation to the city. In Linked Hybrid, Steven Holl "aims to counter the current urban developments in China [by creating] a new twentyfirst century porous urban space" ${ }^{49}$ in the heart of Beijing. 
The project as an "open city within a city" is made of a threedimensional urban space with fused functions. Sky bridges create connections that constantly generate relationships between the inside of the complex and the city.

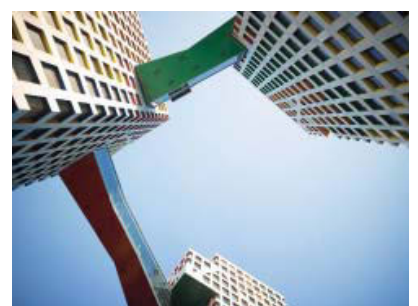

Figure 26. Image from Museum of Modern Art, New York. Project by Steven Holl. Linked Hybrid. (2003)

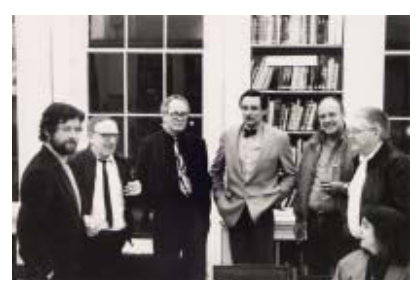

Figure 27. Photograph from Archigram Archives. Archigram Group.
The merging of the public and private realms in Linked Hybrid seems to profit from the combination of horizontality and verticality of the urban form. The verticality saves space in the urban context of Beijing while the horizontal gesture creates a walkable link that animates the whole project and seems to play an essential role in the hybridization process. Such new hybrid types can indeed shape public space in dense environments like it is the case for the city of Beijing. This fascination for circulation and mega-scale was pushed even further through the creation of miniature cities particularly in the 1960s.

\section{Cities within cities}

Along with projects such as Mound, the avant-gardist group Archigram introduced a surprising mixture of varied programs wrought together in a "city-as-a-singlebuilding." ${ }^{50}$ The project designed by Peter Cook exploits the topographical aspect of hybridity in the mimicry of the city as a self-automated microcosms molded to the landscape. The complex interaction between functions as well as the importance of recreation and pleasure in their proposals enhances "diversity as a constructive force." ${ }^{\text {11 }}$ The roof itself is free and becomes a large space for recreation. 
${ }^{*}$ Peter Cook. Archigram. Praeger publishers. (1973) p.120
A space large enough to take the banquet, elephants or gokarts. Ways of adapting from chamber music to ice hockey. An architecture that is made of the event rather than the envelope. So why not forget the envelope?*

Hybrid architecture in this case seems to create alliances with the landscape itself and thus blurs the boundary between what is built and what is nature. This integrated landscape is one of many projects imagined by Archigram which dealt with bigness and enhanced the topographical aspect of hybrid architecture.

Self-contained cities were also often imagined through verticalism. In 1996, Koolhaas proposed the Hyperbuilding for the city of Bangkok. In the form of a combination of skyscrapers, the project integrates the notion of the city-asa-single-building to revitalise an existing area.

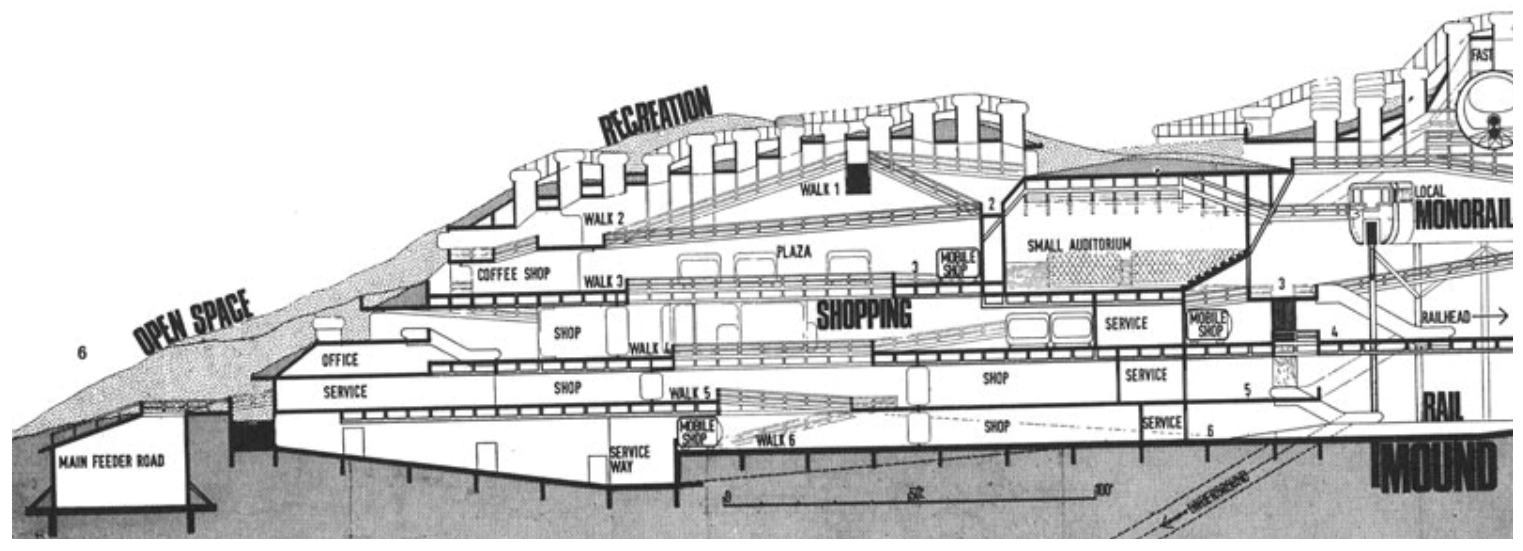

Figure 28. Drawing by Peter Cook.

Project Mound. (1964) 


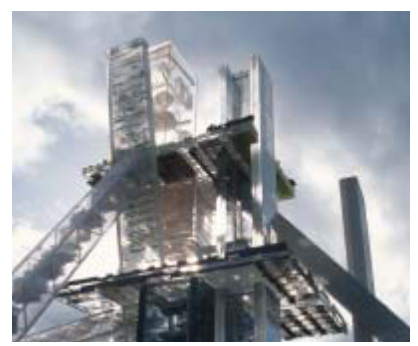

Figure 29.

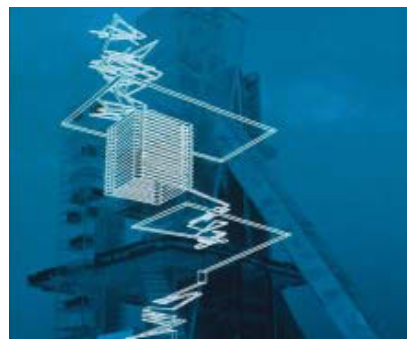

Figure 30. Image by OMA. Hyperbuilding. (1996)

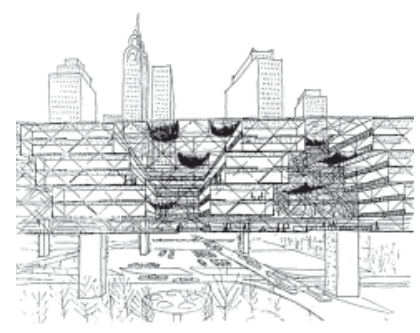

Figure 31. Drawing by Yona Friedman. Ville Spatiale. (1959)
Taking advantage of a hyper-concentrated structure that combines as many programs as a city can offer, the proposal offers a place where people can stay in the city. Without being disconnected from its surrounding environment, the building acts as "a metaphor of the city" 52 and connects artificial streets, parks, districts and boulevards to the existing urban dynamic. Every element supports each other architecturally by means of creating an integrated complex within which a twelve kilometer public promenade links the city to the upper levels. For our purposes here, bigness demonstrated the relevant qualities of hybridization to produce urban quarters of a new kind, rooted into the existing environment and capable of enabling a constant growth of public space in relation to the city.

To Yona Friedman, the city as a "continuous mechanism transforms itself" 53 seems to resonate with this notion of bigness. In Ville Spatiale, a proliferation of events within a single architecture gesture is hovering over Paris as a "blanket of clouds, promising unlimited but unfocused potential renewal of everything." ${ }^{54}$ Ville Spatiale suggests the aerial assemblage of several layers each devoted to specific functions. Such gigantic rigid patterns suspended above towns, according to Friedman, allow for any programmatic mutation to occur.

Advancement in terms of program mixing has certainly been encouraged through the rise of the skyscraper in the 1960s and through the experimentation of utopias challenging scale and functions while enabling promiscuous events within a single idea. 
From Archigram to more recent projects by Steven Holl, Yona Friedman and Rem Koolhaas, strategies where undertaken to organize the independence and interdependence of activities within a large entity. The utopias presented in these experimentations were imagined in terms of pushing the boundaries between programs.

Through bigness, they enabled programmatic hybridizations, proximities, frictions, overlaps and superpositions. Today, many of these utopian ideas seem to get closer to an ideal vision for the future planning of our cities. However, due in part to their lack of spatial indeterminacy between programs and their introverted urban form, the towers of the middle of the last century seemed to have induced the destruction of hybridity. 

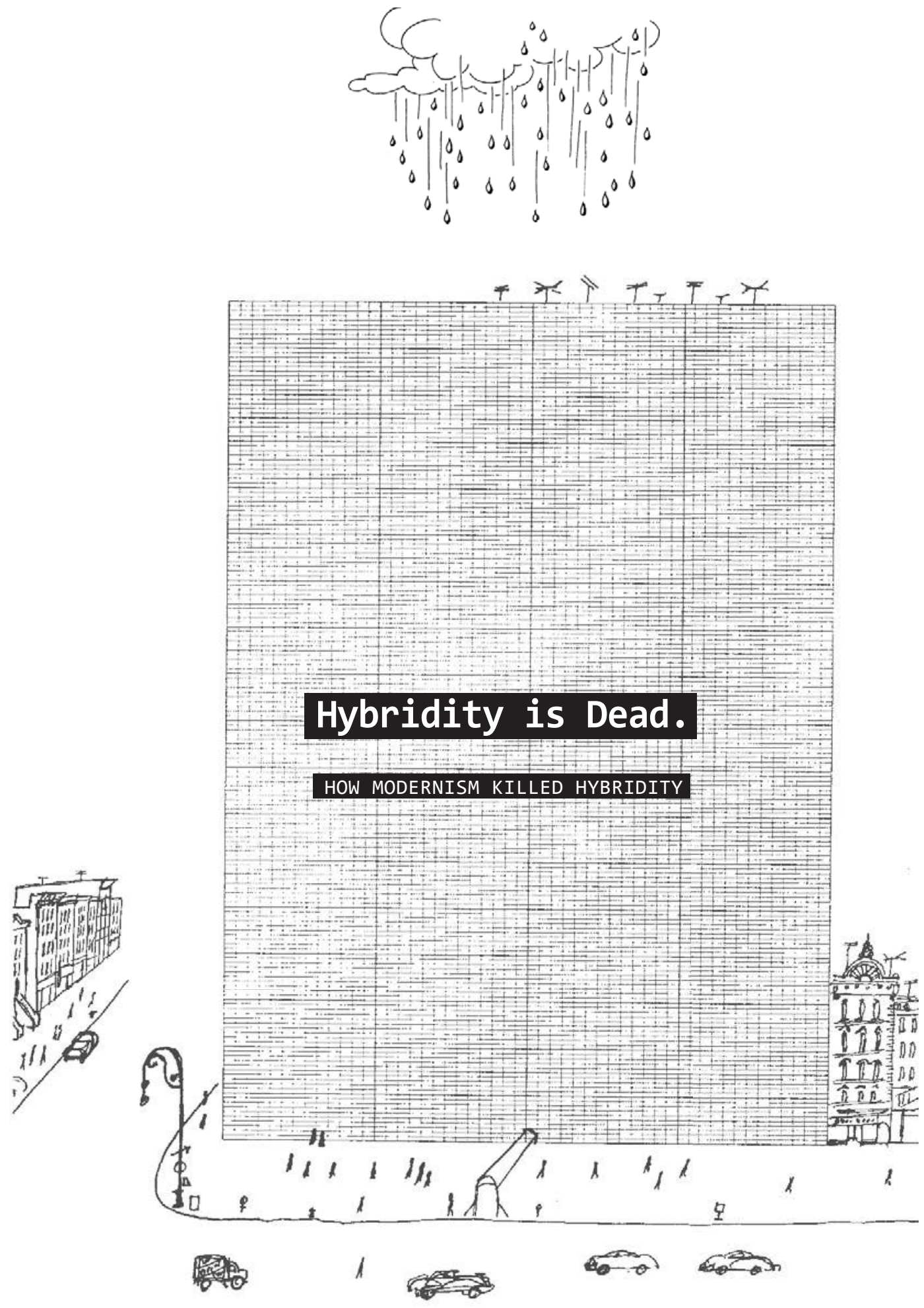

Figure 32. Drawing by Paul Steinberg, The New Yorker Magazine. (1976) 


\section{The Fragmented City}

HYBRIDITY IS DEAD.

${ }^{*} A+t$ research group. This is Hybrid.

Density series. (2014) p.14

\section{What modernism professed as \\ a new and better order, in reality never eventuated as \\ it failed to deal with the inherent complexity of life.*}

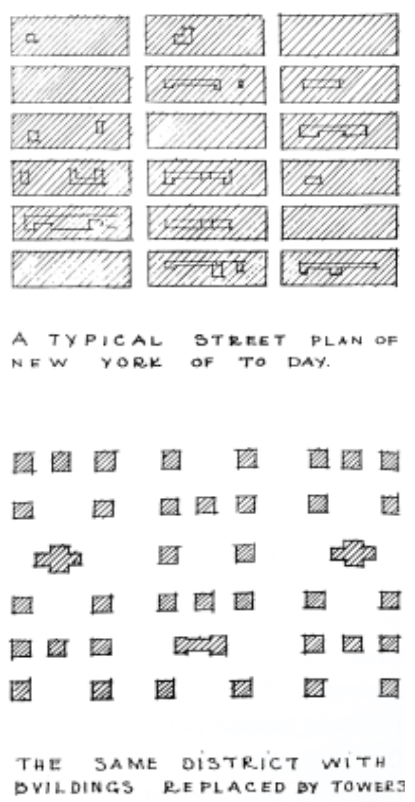

Figure 33. Drawing by Le Corbusier. Radiant City. (1924)
The environment we have built over the past century was in the main based on modernist notions which included fragmentation, isolation and decentralization. The rationalization of architecture imposed by the modernists in the 1960s was felt to ignore the human scale and the irrational world we too often live in. Homogeneous cities based on the idea that everyone should live, work and shop in the same manner began to impose untidy systematics. Human interaction was often missing.

Architecture became an oversimplification of life which inevitably led to a world-wide uniformity of the built fabric. When the city broke its walls and dispersed its content into the countryside, the metropolis evolved out, according to the $\mathrm{a}+\mathrm{t}$ research group, of what seems like "a collection of individualized programmated structures strewn across the landscape." ${ }^{55}$ Whereas these spread design patterns were responding directly to the prerequisites of the post-cold war era, they no longer seem suitable for today's needs. 
${ }^{*}$ Robert Venturi. Complexity and contradiction in architecture. The Museum of Modern Art. (1966) p. 16

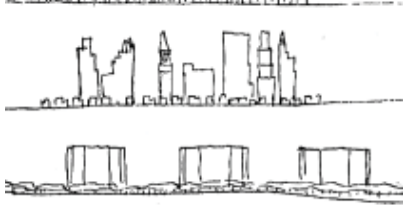

Figure 34. Drawing by Le Corbusier. Radiant City. (1924)
To Brent Brolin, the ideology of modern architecture left out "the human factor [within its] architectural equations." ${ }^{56}$ By imposing a built environment in which they can no longer confront other people and be stimulated, Modernism induced social disintegration. A lively living environment is understood to be fundamentally related to social diversity and integration. Not only compact cities with centralized activities promote such fruitful environments but proximity indeed breeds relationships. While modernists seemed to not adequately comprehend the dynamics of family and community, today we are much more aware that social relationships within a community are complex and overlapping. The built fabric should therefore reflect this complexity.

\section{Participants of the revolutionary Modern Movement acclaimed the newness of modern functions ignoring their complications.*}

\section{Modern Diagrams}

HYBRIDITY IS DEAD.

Through projects such as the Radiant city by Le Corbusier, the Modern Movement established decentralization as the main idea behind the creation of architectural and urban schemes. Thus, the elaboration of utopian ideas for the city of tomorrow enhanced urban sprawl by spreading structures across the territory and segregating functions. 
These diagrams were well-intentioned in response to the apres-guerre period but the failure resides in the immensity of the scale designed for "the automobile age rather than for the needs of man." ${ }^{37}$ Cities were designed for transportation and not for the needs of humans. This delusion on transportation spread the functions across the territory and according to the Canadian urban planner Leonie Sandercock, "wreck damage on the environment, the community, cultural diversity and the human spirit." ${ }^{58}$

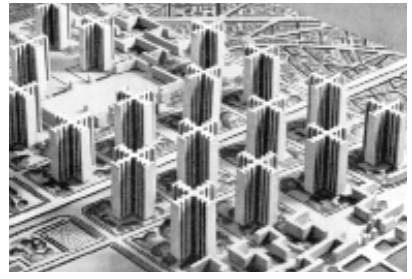

Figure 35.

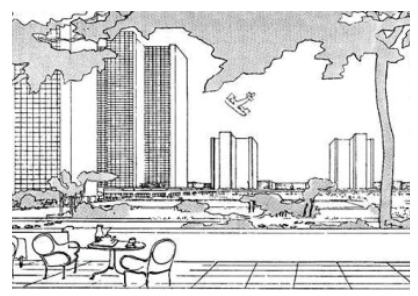

Figure 36. Drawing by Le Corbusier. Radiant City. (1924)
Likewise, Le Corbusier's urban scheme for Radiant City was organized as a system of independent zoning areas each devoted to specific functions and connected through mass transportation systems. Each district had its own organization of high-rise to mid-rise buildings separated by immense green fields. What was intended to become buildings in parks indeed became "buildings in parking lots." ${ }^{39}$ These vast empty spaces were undeniably not designed for the human scale. Hence, the realisation of such utopian projects ultimately resulted in the absence of human interaction. To put it in Avi Friedman's perspective, developers found these "vast open green spaces highly convenient [but in reality], it did not help to foster community life." ${ }^{60}$ This lack of human scale within these early signs of suburbia seemed to have induced a demographic homogeneity. The cost resulting from standalone typologies and decentralized neighborhoods is constantly growing. It is a loss of human and environmental resources to build such poorly designed neighborhoods that inevitably create, to use Peter Blake's extreme statement, a "generations of zombies." ${ }^{1}$ 
It seems obvious today that ideal cities should put forward "pedestrian cities in which dense concentrations of people and many varied activities" 62 engage people in stimulating social interactions. This is mainly what hybridity is about. People gather information about others and about the society around them "by watching, listening and experiencing others." ${ }^{33}$ Dense environments full of surprises and confrontations are respectively where the future of cities should be, not where symbols of alienation such as highways have the leading role. To create invigorating synergies, the hybrid has to evolve in urban environments, ideally dense environments, where it can easily bond to other immediate organisms.

Rem Koolhaas, S,M,L,XL, 1997.

\section{Fuelled initially by the thoughtless energy of the purely quantitive, Bigness has been, for nearly a century, a condition almost without thinkers, a revolution without program.*}

Because of its inaccessibility and introverted character, the skyscraper as designed until recently, despite its infinite interior potentiality for trans-programming, appears to destroy the invigorating aspect of city centers. To the eyes of Modernists, the skyscraper became the ideal solution for the rationalization of architecture through a systemic stacking of individualized functions which soon turned into a fantasy. 


\section{The Skyscraper Fantasy}

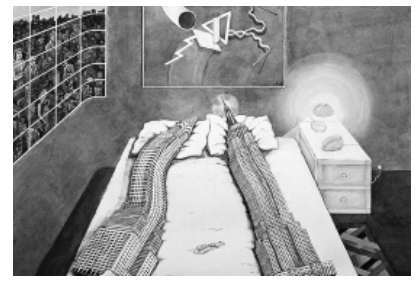

Figure 37. Image by Rem Koolhaas. Delirious New York. The Monacelli Press. (1997)
HYBRIDITY IS DEAD!

Architects such as Mies van der Rohe and Le Corbusier rationalized architecture through what is now considered as one of the most visible symbol of the Modern Movement: the skyscraper. The rise of the Modernist Skyscraper allowed a richer programmation through verticalism. The program overlap may be richer, however, the spatial indeterminacy appears to be lacking. Through bigness, friction between uses is impossible due in part to the absence of spatial relation. The "straightlined rationalist high-rise," 64 as defined by Jane Jacobs, stands against diversity for the will power of uniformity.

In Vertical City imagined by Le Corbusier for the city of Marseilles, sidewalks, placesofconversion and confrontation between citizens are replaced by capsules/elevators. Modern architects created mechanical connections rather than architectural connections. This reorganization of spaces from horizontal to vertical planning created cities with introverted organisms destroying human interaction as it is "simply impossible to animate [their] entire mass."65

The life inside these gigantic structures is fragmented as a result of the stacking of individual privacies. Rem Koolhaas, who brought attention to hybridity in architecture in some of his recent work, mentions how the "incidents on the floors are so brutally disjoined that they cannot conceivably be part of a single scenario." ${ }^{\prime 6}$ 
The spatial division of spaces in the Modern skyscraper fractures the building resulting in the creation of a segregated volume with no interdependent elements.

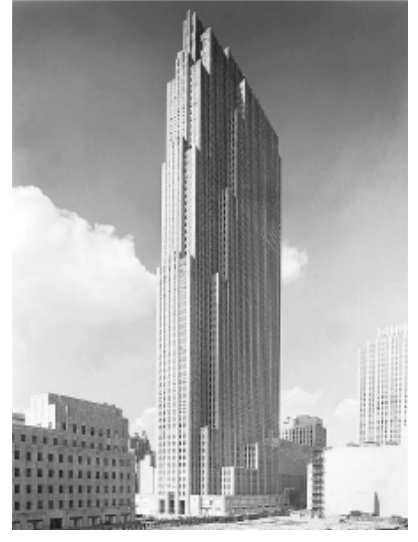

Figure 38. Image from Delirious New York. The Monacelli Press. (1997)
Besides, if we consider Le Corbusier's Ideal City and most of the skyscrapers ever built, the design pattern is dismantled by the inaccessibility of the building envelopes. The hybrid building must be accessible from the city such that it becomes continuously alive with a constant flux of activity. Skyscrapers with their introverted personalities become impenetrable creatures built by "hit-and-run speculators whoconsider thesurface of the earth their private preserve." ${ }^{67}$

Modernization promoted the status of individual buildings through curtain walls "reflecting back and forth into each other and into infinity."68 Bigness seems incapable of establishing an exchange with the city as it is competing with it. The resulting individualism also influenced man himself as it isolated him from others.

The misconception of human life and the false step made by the pioneers of the Modern Movement guides us toward the redevelopment of hybrid architecture in contemporary cities. Hybridity in architecture is heading towards the creation of a new logic in urban planning with land scarcity and density in the foreground. 


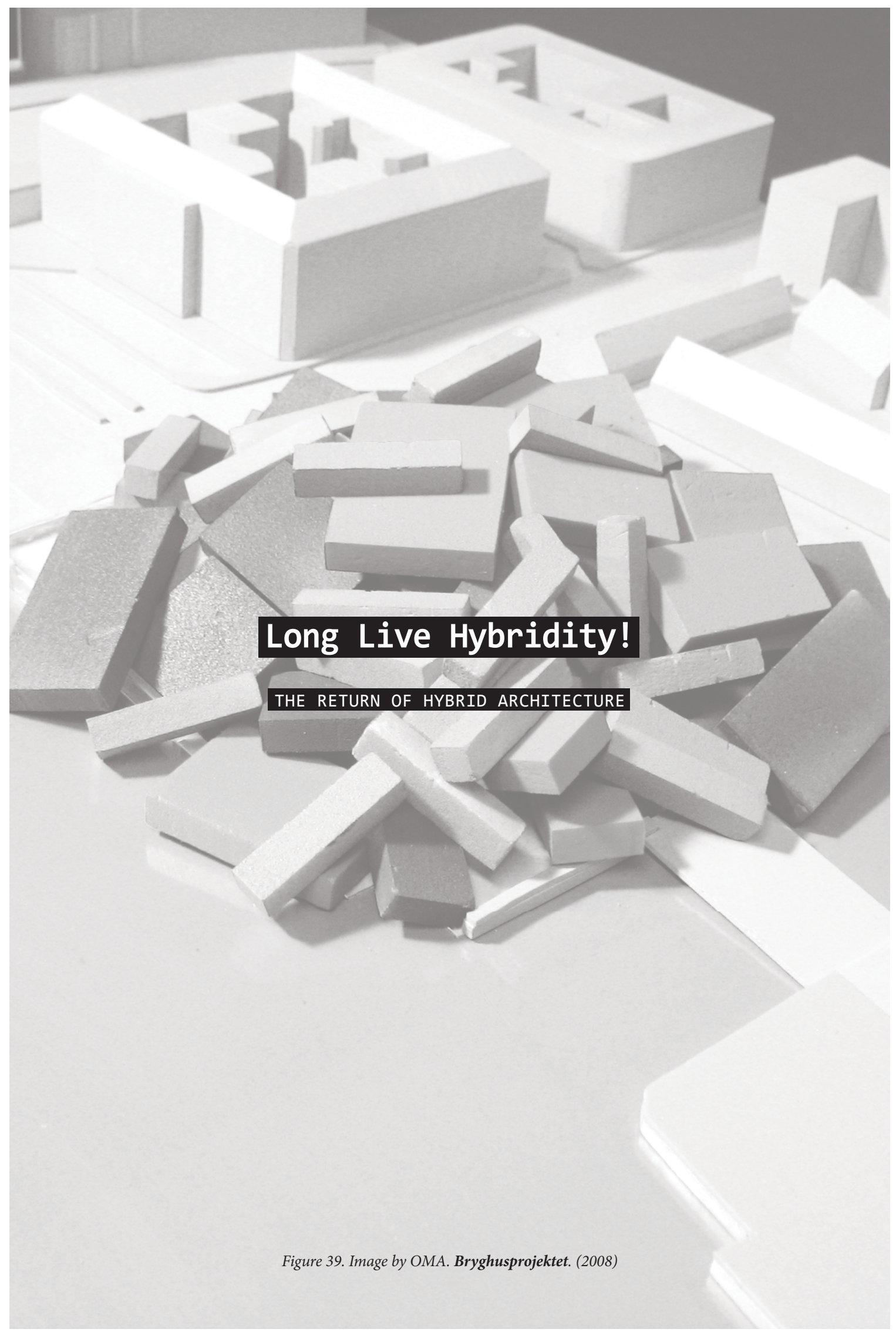




\section{Hybrid Architecture to the City}

LONG LIVE HYBRIDITY

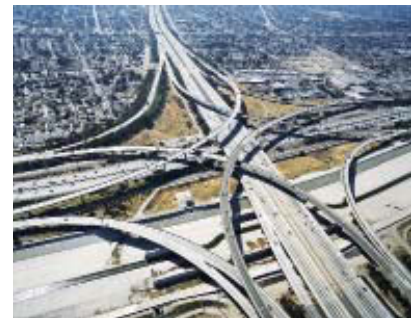

Figure 40.

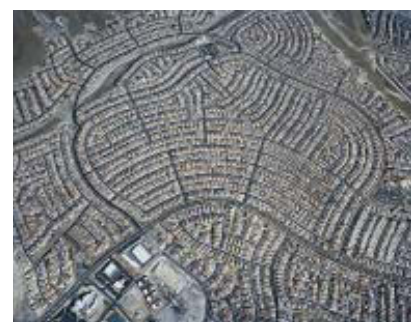

Figure 41. Photograph by Christoph Gielen. Decoding the hidden circles of suburbia. (2014)
As Jane Jacobs pointed out in the 1960's, "the dramatic increase in car traffic and the urban planning ideology that separates the uses of the city and emphasizes free-standing individual buildings" 69 will kill urban space and the lively aspect of cities. The geographic dispersion brought resulted urban sprawl induced by Modernism degenerated city centers and encouraged increasingly "disconnected destinations." ${ }^{\prime 0}$ Today's cities are often seen as a collection of singular stand-alone buildings surrounded by parking lots and large roads. Cities thereby lose character as unpredictable meeting places. If we are to better understand the context in which hybrid architecture evolves today, we must then address the urban scale.

The constant growth of the population is currently one of the general global issues as it is changing radically our cities and forcing city planners to rethink urban density. Cities are growing fast and will continue to grow at such rate that "in the next thirty years, two out of three people will live in cities." ${ }^{\prime 1}$ Yet according to Stewart Brand, ${ }^{72} 1.3$ million new people move into cities every week which sums up to almost 70 million every year. Taking into account this likely scenario, high-density architectural forms and wellthought density represent the most viable models for the near future. 
In addition to this radical population increase in urban centers, architecture is evolving in a constantly changing context with social, political, environmental and economic components. In these circumstances, the design of built environments capable of housing a growing population while dealing with the constant decline of vacant land represents a major challenge.

Hybrid architecture can then go beyond the domain of architecture and enter the realm of urban planning by responding to such concerns. Densification, diversification and intensification of land and uses are undeniably the basis of its achievement and compactness.

\section{The Compact City}

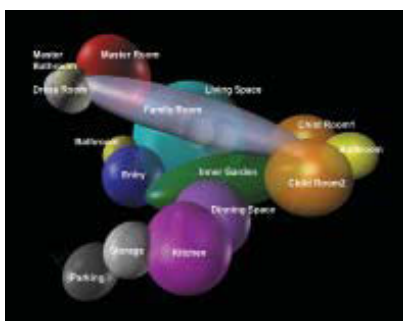

Dense urban environments appear to be ideal scenarios for hybrid architecture as they promote the compact city instead of the dispersed city. As hybrid buildings are mixed organisms that enjoy "dense and fruitful atmospheres," they must evolve in dense environments to fulfill their Figure 42.

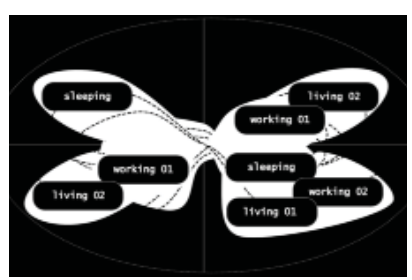
raison dêtre. Indeed, the compact city is based around complex, diversified, interrelated and dynamic associations which are fundamentally linked to the nature of hybrid Architecture. There is an endless list of advantage to densely built cities. As they take "less space, land and infrastructure, they require less maintenance" ${ }^{174}$ which leaves unoccupied Mobius House. (1993) spaces that remains available for future developments or for other activities. 


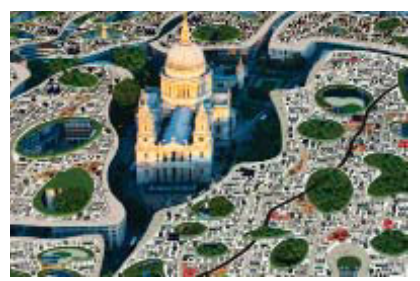

Figure 44 .

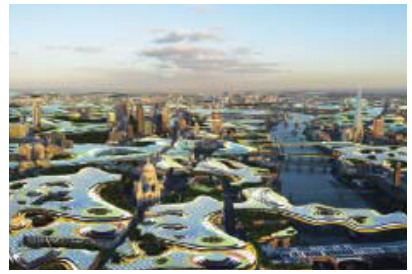

Figure 45. Image by Clive Wilkinson Architects. Endless Workspace. (2015)

${ }^{*} A+t$ research group. High-rise mixed-use buildings. (2008)
Moreover, the proximity enabled by densification creates a greater chance for interactions between activities and people. These frictions tend to enhance the opportunity for social interaction and to generate "environments of rich activities."75 Areas with higher density levels may induce other essential aspect such as intensity and diversity, in the making of stimulating cities. The living conditions offered by the hybrid building are improved not only through the alliances created by trans-programming but also with the qualities generated by density. Thus, by integrating principles of high-density, hybrid buildings tend to be more efficient while conserving land resources as well as reducing distances and energy use.

\section{It is an opportunist building, which makes the most out of its multiple skills, a key player which revitalises the urban scene and saves space.*}

According to the Dutch architect Rudy Uytenhaak density is defined as "the degree of penetration of the public domain into the private domain." ${ }^{36}$ Through the balance between built space and non-built space, density aims the optimization of land use. The study of density however does not mean maximizing density in terms of floor space but optimizing the mixture of ingredients within a building. This assemblage is achieved in high-density architectural forms through a "mutual proximity of urban activities, and therefore urban dynamism and efficient land use."77 
There are two forms of density, the physical density and the perceived density. The physical density corresponds to the "numeric measure of the concentration of individuals in a certain geographic unit"78 while the perceived density is defined as the spatial objective indicator which is strictly related to the psychological sense of space. In other words, perceived density represents one's perception of an estimated number of people in a given area. For instance, dense environments including increased noise, lack of intimacy and various sources of stress such as crowding relate to perceived density. Such examples of bad density are numerous in many cities in the world today, thus, "finding new ways to design high-density built environments is a necessity." ${ }^{79}$

Population density relates to quantity and defines the number of individuals per given area. However, "it is not a question of fitting as many homes as possible" 80 nor it is a question of "reducing the voids." ${ }^{11}$ Whereas "proximity is the key to the city's appeal," 82 it must be strictly linked to quality. Densification alone however does not automatically produce interesting cities. Buildings need diversity and intensity in order to produce together "intelligent puzzles [with] high-quality interior and exterior domains." ${ }^{33}$ Yet how does this connect to escalating land values? 


\section{Escalating land values}

Land value is constantly growing due to inflation, speculation and scarcity. The hybrid building tends to respond to these contemporary concerns and saves space by condensing various activities under its roof. By densifying its usage, it seems to create a "centripetal force" 84 on its surrounding context such that it can counteracts the effect of the "centrifuge force" 85 produced by sprawl. Besides density, two other components come into play: diversity and intensity.

The friction existing between disparate programs then creates constant occupation which intensifies land use. Density, diversity and intensity may contribute to a sustainable development by shortening distances, encouraging walking instead of driving and by making the maximum out of one land. Hybrid situations propose "intense environments of cross fertilisation" 86 that encourages the interaction between citizens as they are "sharing facilities, amenities and public spaces." 87

Well thought high-density built environments can achieve a balance between privacy and interaction. The combination

of programs such as residential units, public spaces and cultural facilities can support "positive interactions that reinforce a sense of community." 88 The exchange between citizens and uses takes form in complex interactions that are likely to be richer in dense areas. Recent researches in the neuroscience field demonstrate the relation between emotional intelligence and people born in larger cities. 
To Jan Gehl, cities that promote accessibility to all groups of a society are serving a "democratic function" 89 in which people tend to benefit from "a greater understanding of each other by sharing the same city space." 90 Thus, the qualities making the city a lively space decreases the chances for people to move into gated communities. The built physical environment influences our behaviour in situations of social interactions as well as individual experiences. Unpredictability and spontaneous actions that characterise hybrid architecture contribute to the making of enjoyable cities while "harnessing images of metropolitan life, highlighting diversity of experiences, programs and people." ${ }^{11}$

The tendency towards a more and more dynamic use of the land seems irreversible. To activate cities, we must deal with mixtures of uses, not separate uses. The various studies concerning density in urban contexts conducted by Rudy Uytenhaak lead to the conclusion that the need for mutual proximity requires space for territories that overlap, places in the city that different subcultures can use, simultaneously or at different times." ${ }^{92}$

\section{4-hour cities}

The proximity and overlapping of usage can be enhanced through time spread. People must appear at different times to produce diversity and intensity of land and uses. The significance of time spread seems essential as it ensures a continuity of movement. 
To Jaime Lerner, "one sector would help the other because both would work in sequence, keeping the city alive with commerce day and night." ${ }^{93}$ This constant activity also contributes to make streets safer. The mixing of uses according to time prevents the creation of part-time districts.

According to Jane Jacobs, there are two kinds of diversity which must be combined according to the 24 hour clock; primary and secondary diversity. The primary diversity corresponds to those uses which, "in themselves, bring people to a specific place because they are anchorages." ${ }^{\prime 4}$ Offices, factories and dwellings are considered to be in the primary diversity collection. Then, one must combine elements of secondary diversity which "contains enough that is unusual or unique, [that] is seemingly can and does become, in its accumulation, a primary use itself." 95

On their own, primary uses do not seem to generate any kind of diversity. But when combined, effectively, with secondary uses which allows for people to go in and out at the same time, then, we can assure that the time spread had an "economically stimulating effect" The more interlaced the uses are, the more they seem to generate diversity. But again, this must occur twenty-four hour a day.

How can our cities engender enough alliances among uses and enough diversity throughout enough of their lands to sustain their own development? 
The following study experiments with time and creates potential mutations between programs. Through the mapping of time periods in which certain programs are active, the time-study aims to create combination of uses in order to maintain a constant activity within the future project proposal.

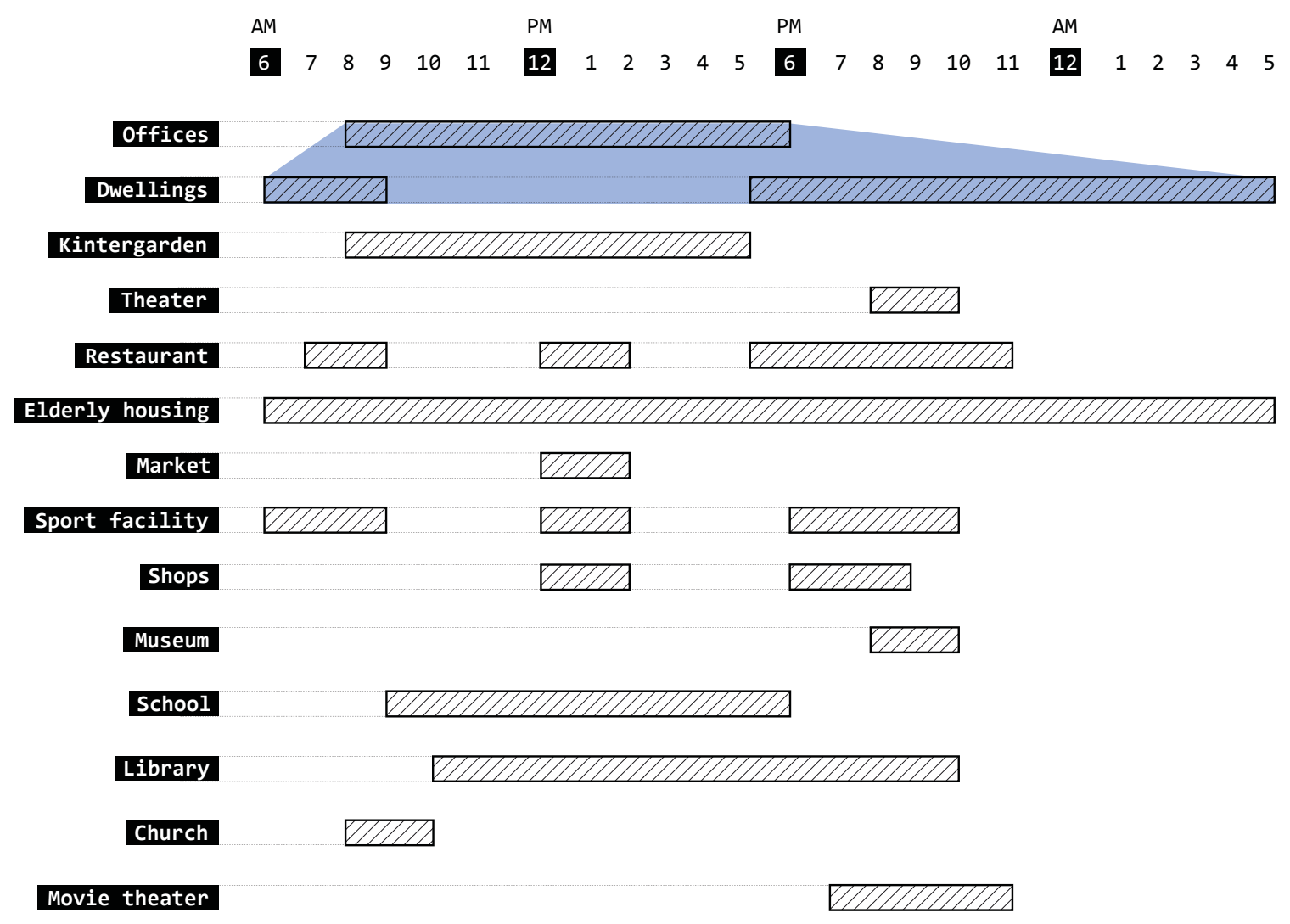

Figure 46. 


$$
\begin{array}{llllllllllllllllllllllllll}
\text { AM } & \text { PM } & 10 & 10 \\
6 & 7 & 8 & 9 & 10 & 11 & 12 & 1 & 2 & 3 & 4 & 5 & 6 & 7 & 8 & 9 & 10 & 11 & 12 & 1 & 2 & 3 & 4 & 5
\end{array}
$$
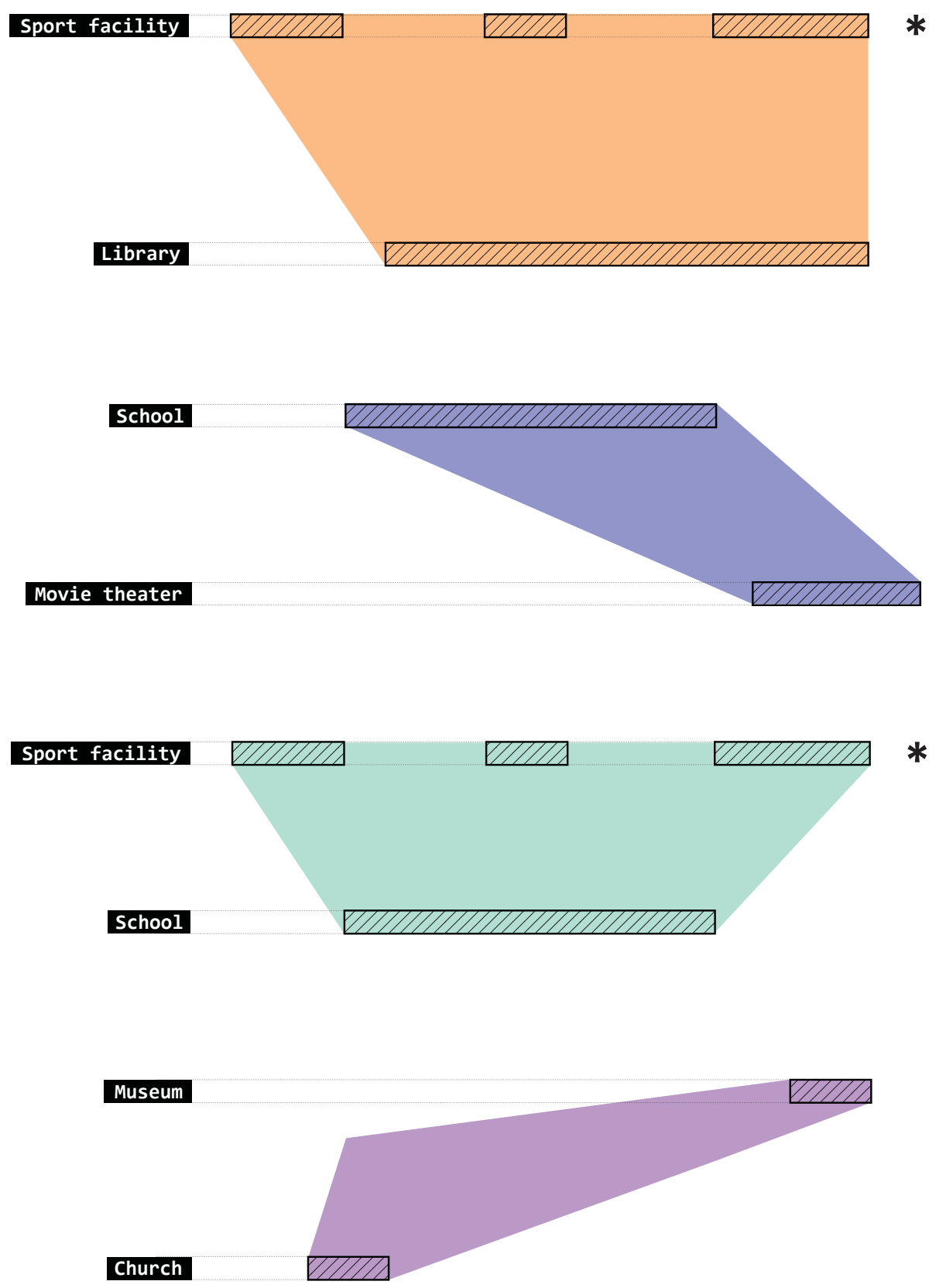

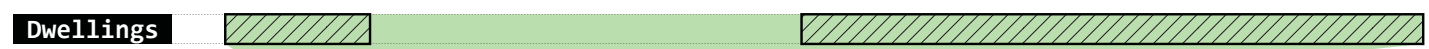

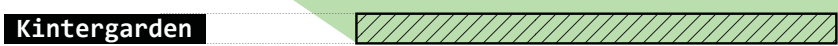

Figure 47 

AM
PM
PM
$\begin{array}{lllllllllllllllllllllllll}6 & 7 & 8 & 9 & 10 & 11 & 12 & 1 & 2 & 3 & 4 & 5 & 6 & 7 & 8 & 9 & 10 & 11 & 12 & 1 & 2 & 3 & 4 & 5\end{array}$
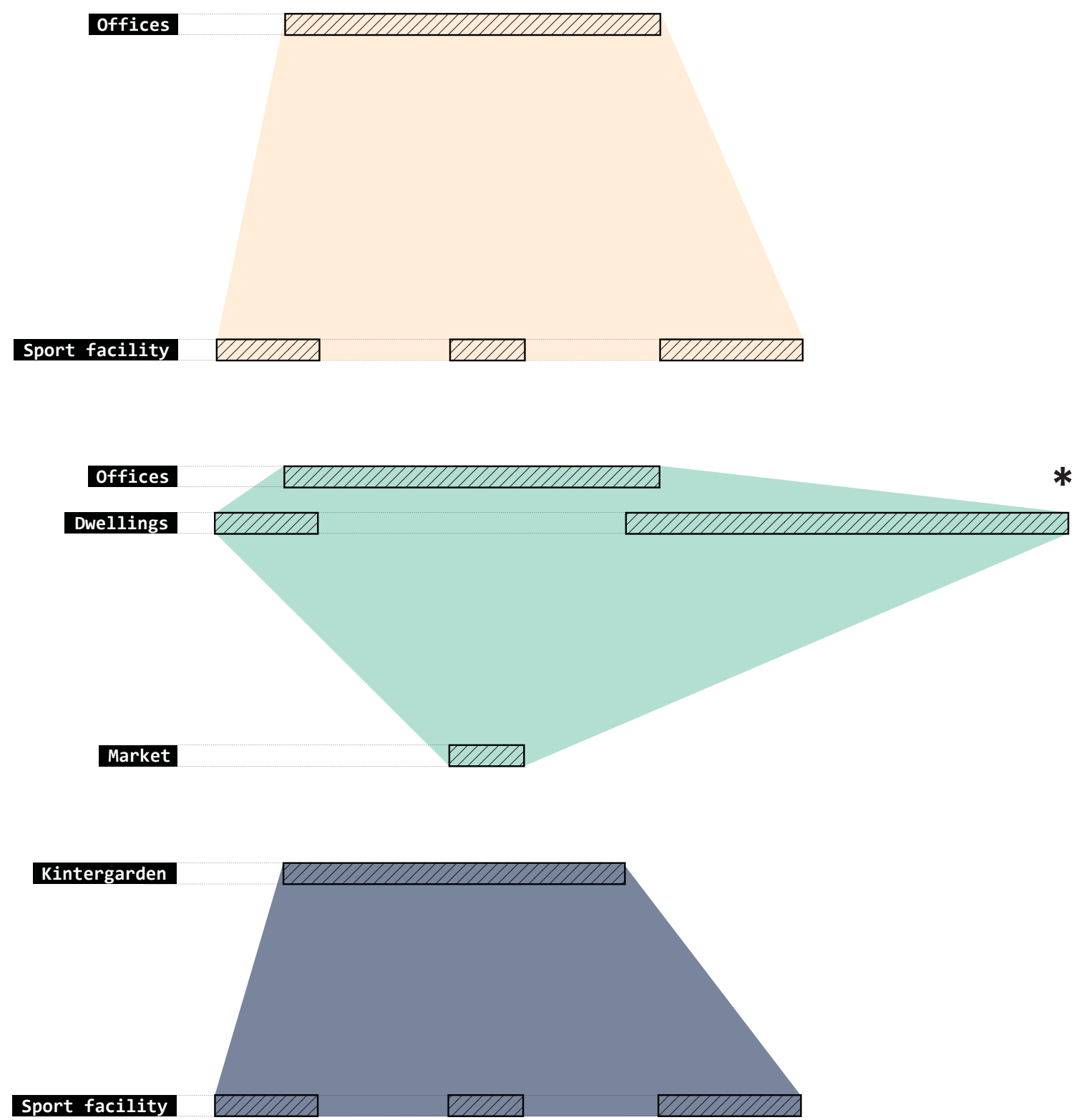

Figure 48 . 

$\begin{array}{llllll}\text { AM } & & & & & \\ 6 & 7 & 8 & 9 & 10 & 11\end{array}$
$\begin{array}{llllll}\text { PM } & & & & & \end{array}$
$\begin{array}{cccccc}\text { PM } & & & & & \\ 6 & 7 & 8 & 9 & 10 & 11\end{array}$
$\begin{array}{llllll}\text { AM } & & & & & \\ 12 & 1 & 2 & 3 & 4 & 5\end{array}$
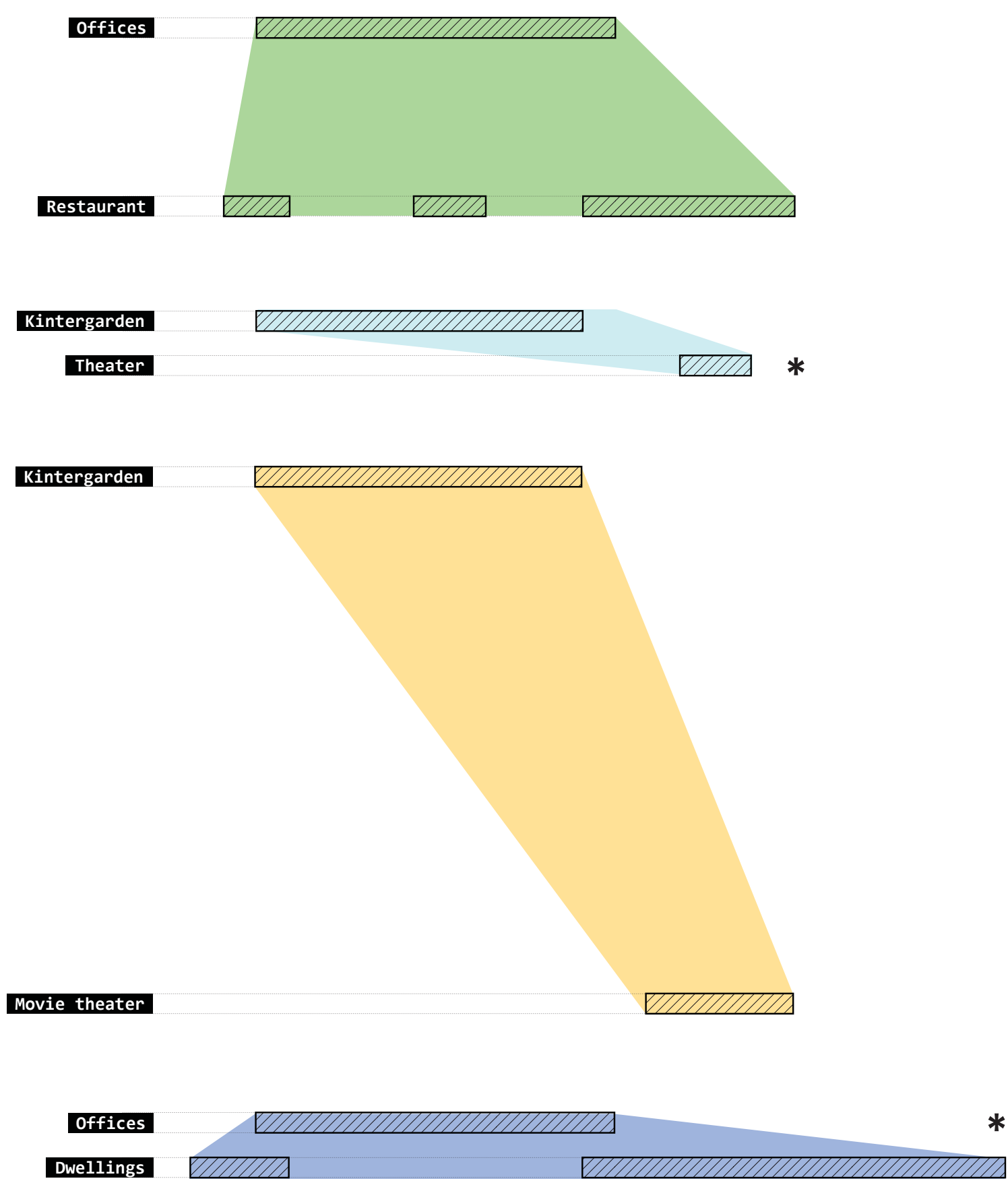

Figure 49. 

$\begin{array}{llllll}\text { AM } & & & & & \\ 6 & 7 & 8 & 9 & 10 & 11\end{array}$
PM
PM
AM
$\begin{array}{lllllllllllll}2 & 1 & 2 & 3 & 4 & 5 & 6 & 7 & 8 & 9 & 10 & 11\end{array}$
$12 \quad 1122 \quad 3 \quad 4 \quad 5$

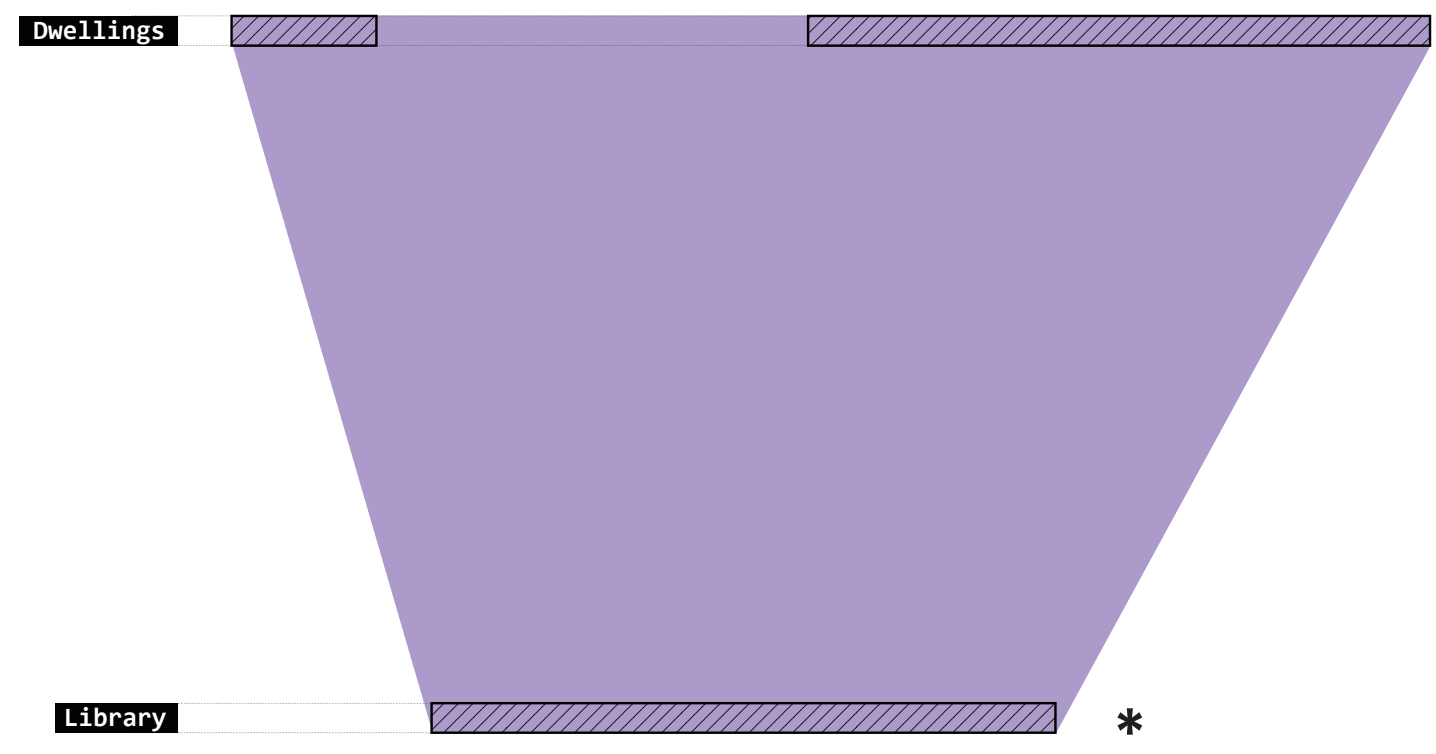

Dwellings DIDADA

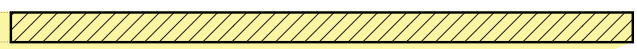

Market

सIIIA

Dwellings

QIIIIDA

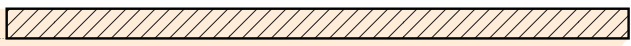

Sport facility

पIIIID

DIIIA

DIIDIDIA *

Figure 50 


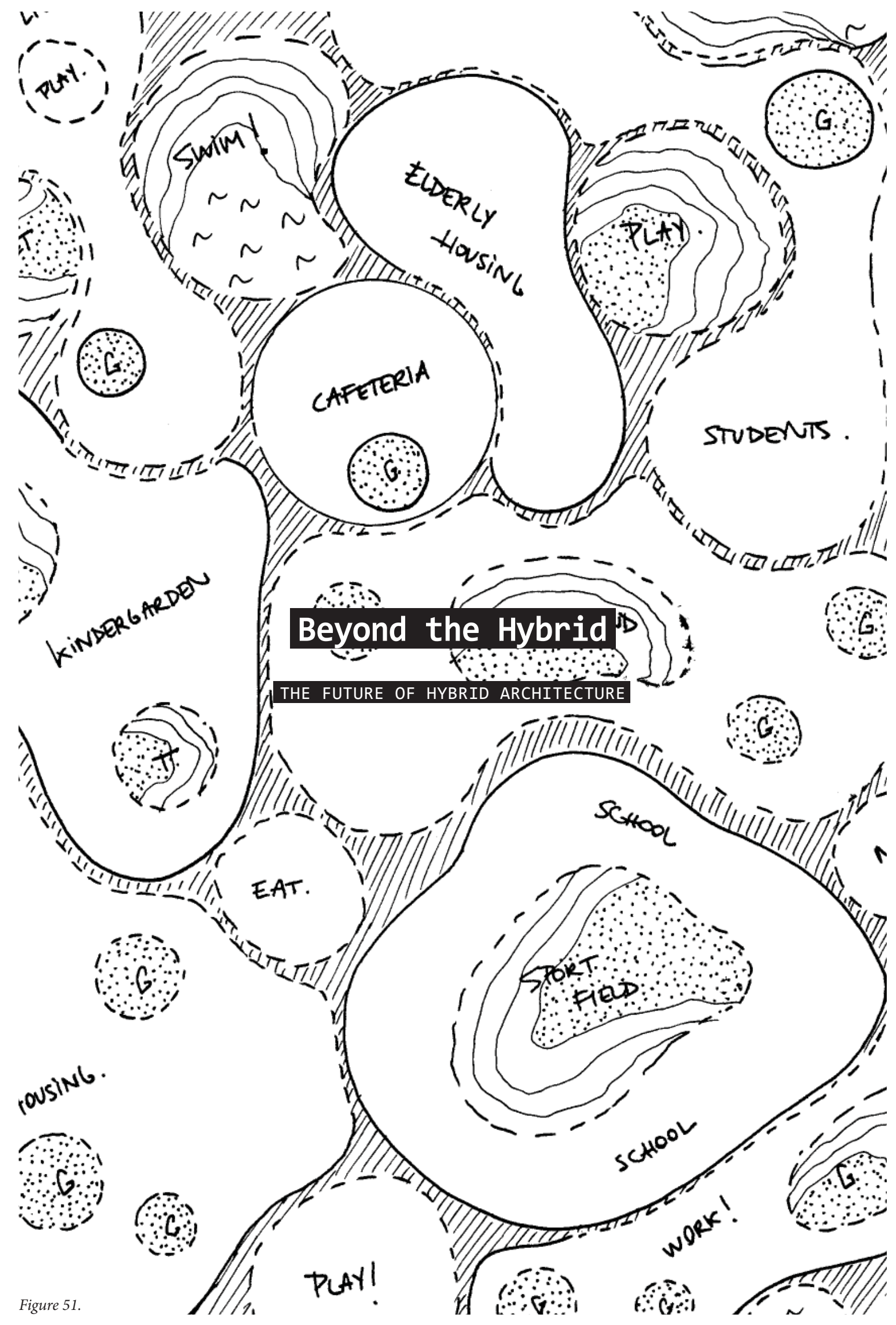


We must now get beyond the hybrid. While being responsive toward their respective contexts, hybrid buildings should act as catalyzers to invigorate the complexity and dynamism of the city in which "people encounter social diversity and gain a greater understanding of each other." ${ }^{97}$ More compact cities seem to be imperative in the making of dynamic cities.

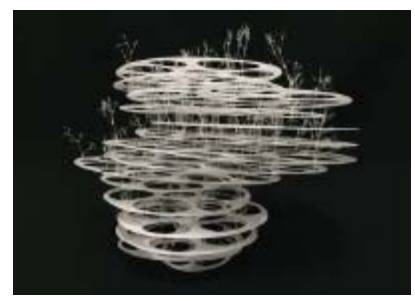

Figure 52.

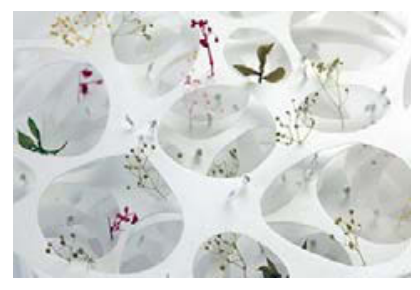

Figure 53. Image by Sou Fujimoto Architects. Energy Forest. (2013)
New methods of approaching urban densities is empowered by hybrid architecture as it addresses the way in which buildings and their functions are arranged and compressed in relation to one another. Density, diversity and intensity appear to be utilised through hybrid architecture as a tool for regenerating city centers. Such concepts clearly tend to hybridize architecture. However, can we state that hybrid buildings truly produce hybrid situations?

What then makes a hybrid hybrid? In today's world, it seems that the infrastructures that inhabit our cities must be versatile enough to adapt to different usages and be designed in order to maximise intensity and maintain a constant activity. If we consider that each space is devoted to a specific function, even if several functions are combined within a building, the overall idea may not be hybrid. Every time we assign a use to a space we create boundaries. How can we diffuse these frontiers? How can we imagine this in a project? 


\section{Interchangeable spaces}

BEYOND THE HYBRID

Several studies such as the time-study will allow for a greater mixture between programs and intensity of site usage. Now the question that must be addressed relates to the fact that infrastructure designed for specific programs are not ensuring a constant activity. How can we think of spaces that can change vocation on short and/or long periods of time? Function replacement, or what we could call interchangeable architecture allows for different user groups to use the building over the course of the day.

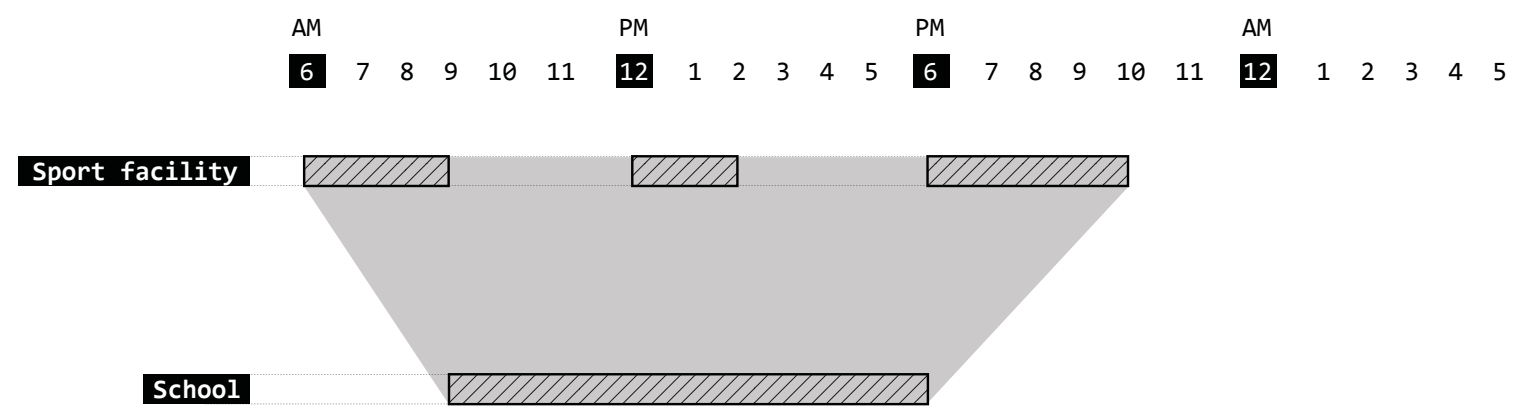

Figure 54

If we consider the school and sports field hybrid that came out of the previous time study, generally speaking, the school isn't active on evenings and weekends. Can the urban form and design of the infrastructure be versatile enough to allow for the school to mutate into an opened stadium when needed? Now, based on the time study we know that sports field and related sports events are mostly held on evenings and weekends. Can such programs working simultaneously produce hybrid situations? What urban form can promote a greater friction between such programs? Can we call this hybrid architecture? 


\section{Urban sponge}

BEYOND THE HYBRID

Location: Montreal, Canada

Programs: Dwellings, offices, sport facilities, kindergarten, school, playgrounds, parks and gardens, markets, theaters and movie theaters, library, restaurants and unprogrammed spaces and promenades.

Size: $165500 \mathrm{ft}^{2}$

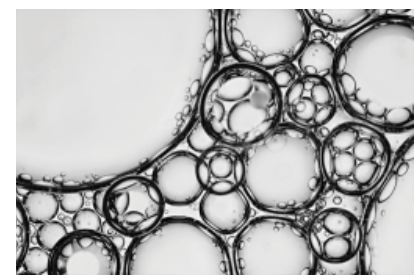

Figure 55 .

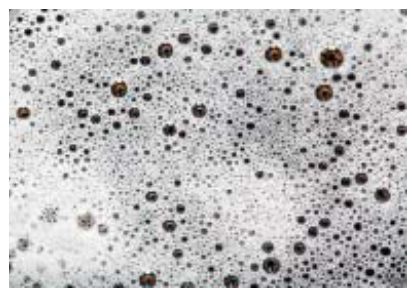

Figure 56.

As an attempt to create a hybrid event in the city and respond to ten conditions established throughout this thesis, Urban sponge relates on diversity, density and intensity to revitalize and animate a barren area of Montreal. The site, located at the edge of Little Italy and Mile-end neighborhoods, seems ideal for the insertion of a hybrid organism. While absorbing urban flows, the project creates new connections and movements through the site such as to regenerate this area struggling for life. Urban sponge can be read as a celebration of complexity featuring programmatic mutations.

Relating on proximities, frictions and overlaps, hybrid patterns are organized collectively based on strategies focusing on interdependence rather than independence such as to create an urban area of a new kind working 24 hour a day. In addition to these hybrid combinations, the proposal features unprogrammed spaces such as to produce an unfinished architecture constantly changing and evolving over time. 
In this on-going proliferation of events, hybridization materializes itself through contamination rather than purity with an effort to produce a new situation that will stimulate and revitalize this lifeless area of Montreal.

Hybrid architecture through ten conditions

\section{Condition \#1:}

Encourage the revitalisation and/or bring back to life a certain urban area.

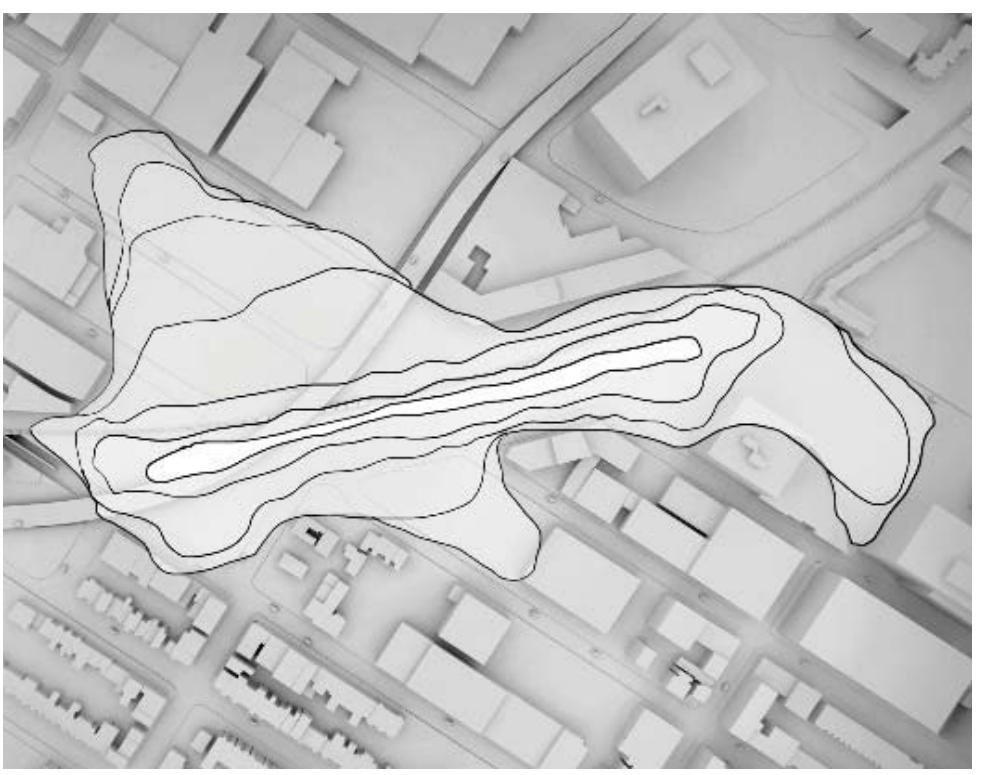

Figure 57.

The insertion of a hybrid organism at the edge of these two neighborhoods aims to revitalize the area and create new centripetal forces and movements. The insertion of a new density will enable a rebirth of the site and create new connections between districts that were once lively and contributed highly to the Montreal's cultural identity. 
Create links between parts of the city allowing it to act as an urban generator.

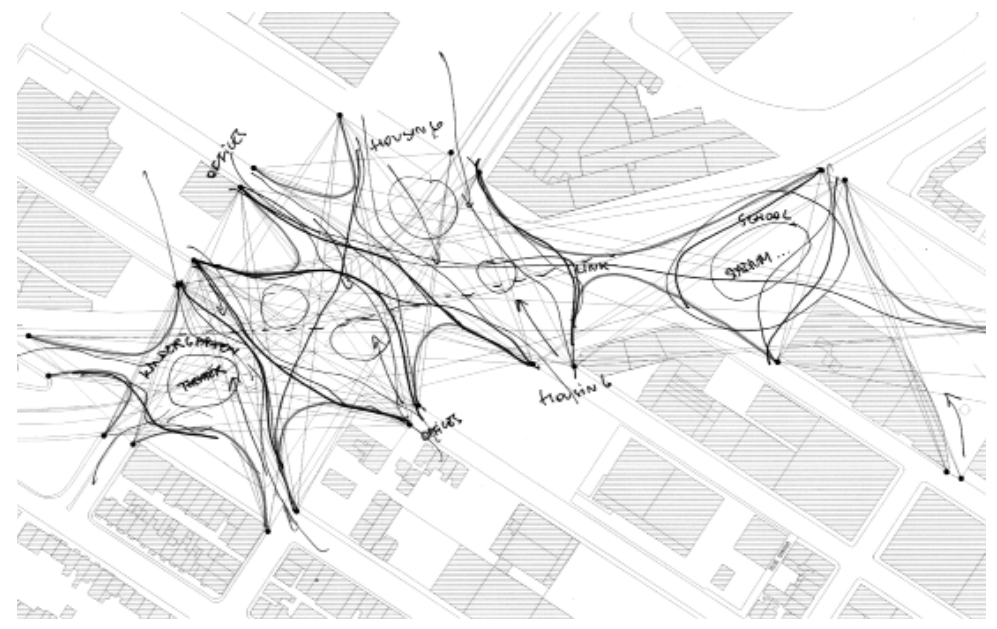

Figure 58.

While Tschumi's inhabited bridge proposal was suspended over water and linking two parts of Lausanne, Urban sponge connects two neighborhoods of Montreal using a similar urban strategy. Hovering like a cloud over an empty green field, named Champs-des-possibles by the locals, the project anchors its tentacles in the existing sidewalks on both sides of the site such as to create new links between both districts. Taking advantage of its sprawling shape, Urban sponge draws people in and out as freely as possible. As a sponge, it absorbs traffic and releases it. The proposal suggests an urban composition strategy that stitches together parts of the city while enabling a dialogue with other urban landmarks and relationships with the existing fabric. Here, we see movement as generator of hybridity. 


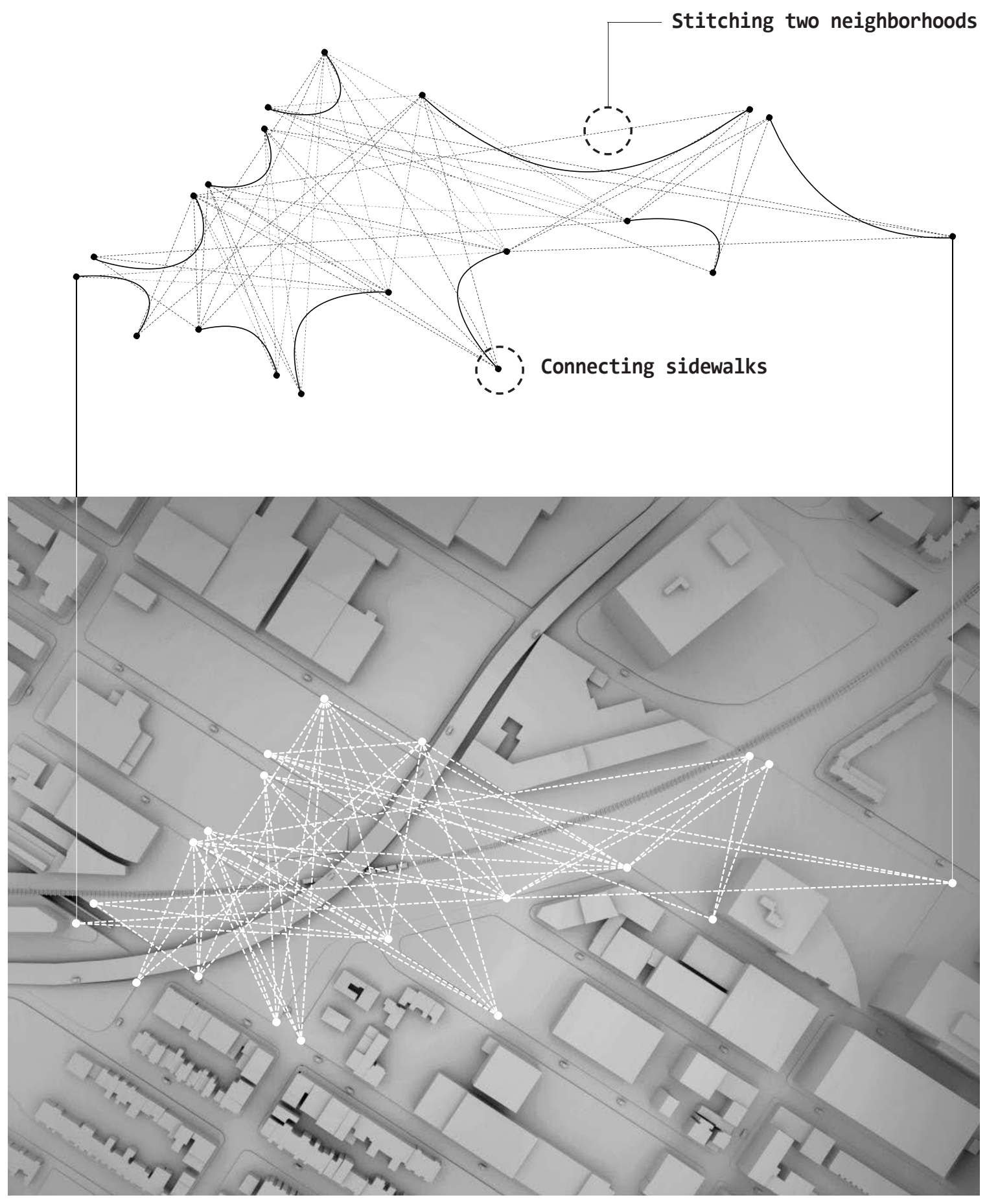

Figure 59 


\section{Form a mutation between landscape and architecture.}

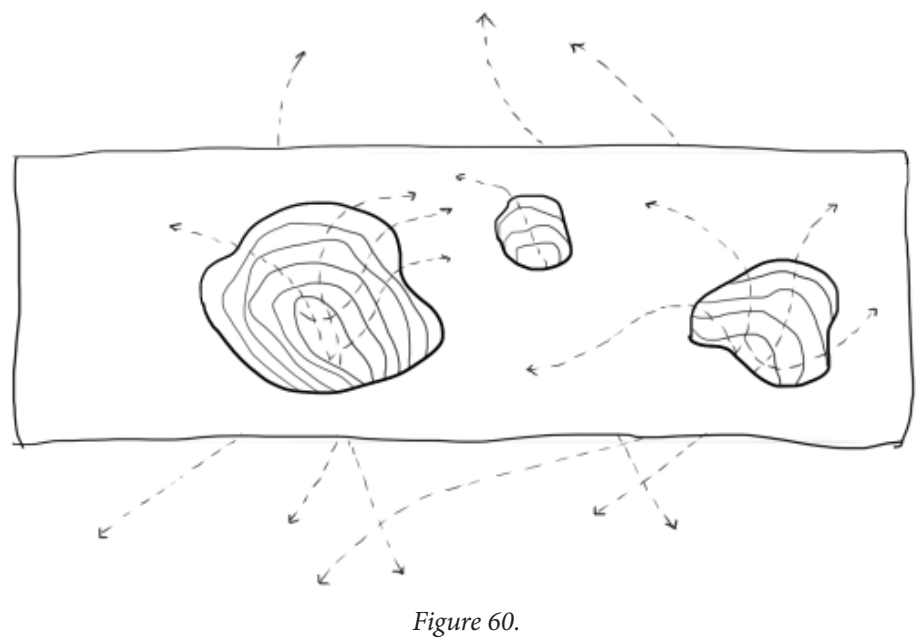

Many locals expressed their vision of what should become the Champs-des-possibles. The general opinion about this vacant land was to leave it as it is. However, most of them agreed that there should be some kind of revitalization in the area while maintaining the field's natural aspect. The project proposes an infrastructure that will mostly be hovering over the surface of the earth.

The natural aspect of the field will be preserved. Urban sponge therefore spreads over the landscape and connects with it at various locations throughout the site. The malleability of the earth's surface creates a strong diagonal movement through the project which contributes to the hybridization of landscape with architecture.

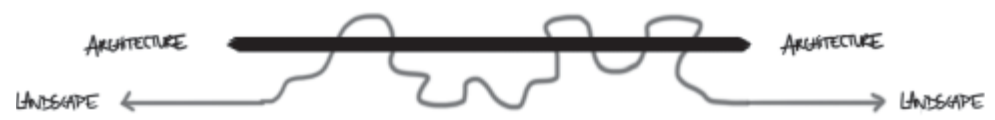

Figure 61 


\section{Create intense environments of cross fertilization.}

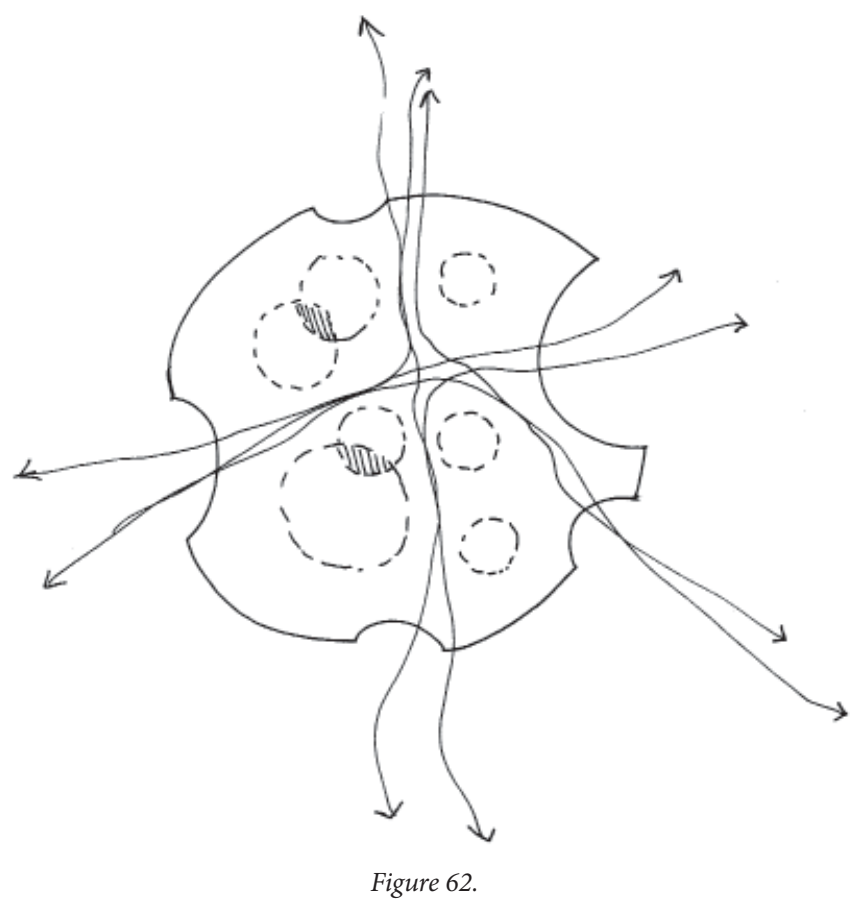

Porosity and permeability are key elements to this project as they allow for an easy movement throughout the site. Unprogrammed promenades are inserted between activities to so create spaces that are exclusively activated by the motion of bodies and favor exchange between people. These in-between spaces are creating new types of spaces which enable movement between the programs to animate the entire mass. To follow Tschumi's theory, these spaces are made of accidents and allow for "unexpected events to happen." ${ }^{98}$ Urban sponge therefore suggests an incomplete and indefinite frame of urban events through the establishment of ephemeral relations between uses. The project will therefore evolve through flexible programmed hybrid spaces as well as spaces free from architecture which can be adapted to future needs. 


\section{Condition \#5:}

\section{Share intensities between programs.}

Unexpected combinations of programs create new spatial configurations in which disciplines merge and crossfertilize to allow for new architectural forms to emerge. Extreme programmatic mixtures aim to intensify and accelerate the urban experience. The transprogramming of activities and the unusual relations between them enhances the lively aspect of this urban area. What happens if we combine a swimming pool facility with an elderly housing complex? Can the typical courtyard become an indoor pool working three hundred and sixty-five days a year?

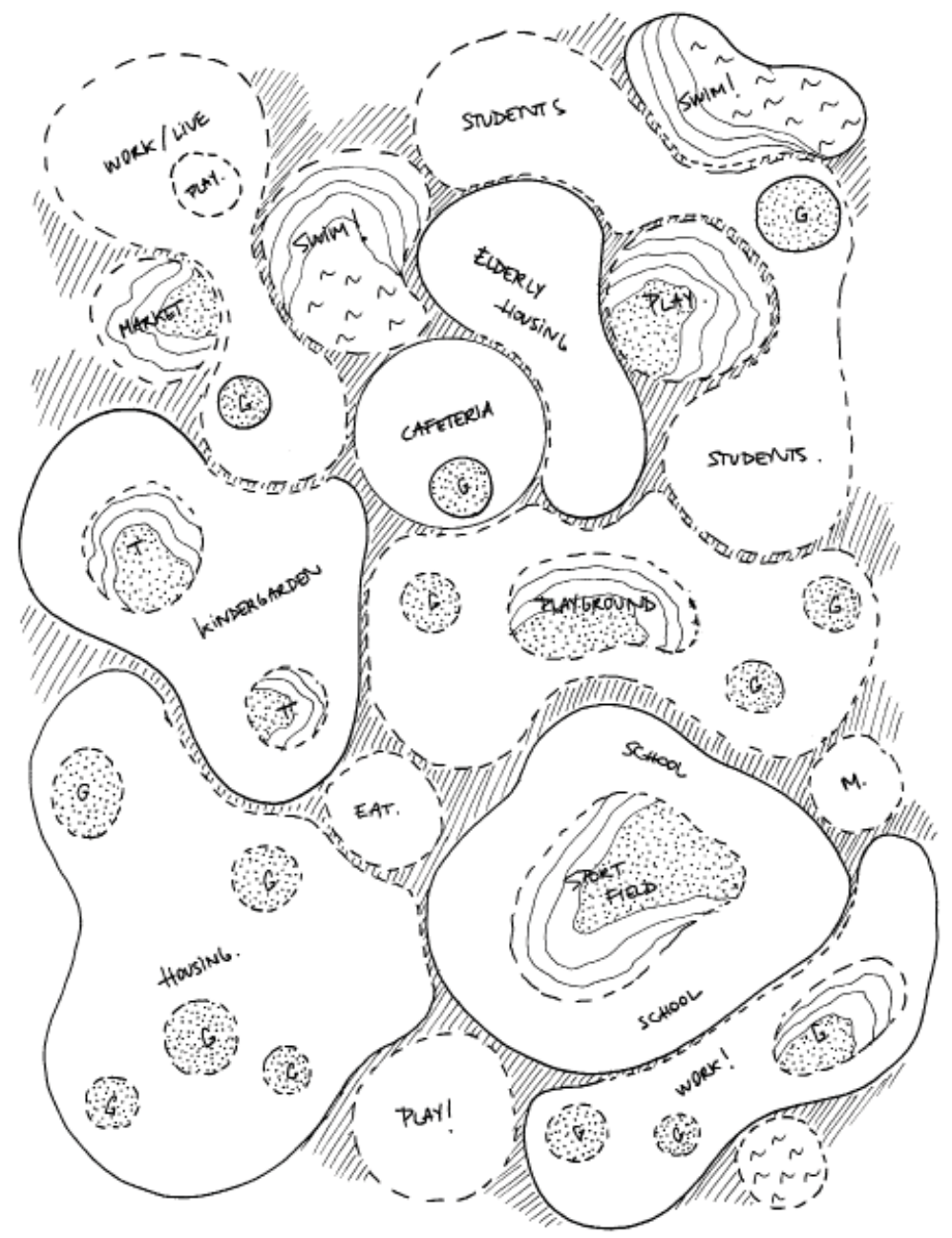

Figure 63 
The proximity and overlapping of these two programs can change radically the way elderly people live. Being close to water can have a huge impact on their everyday lives. Not only it can allow them to benefit from a healthy lifestyle, it can also draw people in and there reinforce social interaction as well as diversity. What can we offer best to elderly people than a place where they can exchange and be stimulated by others? Following the programmatic combinations that emerged from the time study, we create mixtures that will allow a constant activity within the area allowing the building to work full-time.

\section{Condition \#6:}

Encourage full-time buildings rather than part-time buildings (intensity of usage).

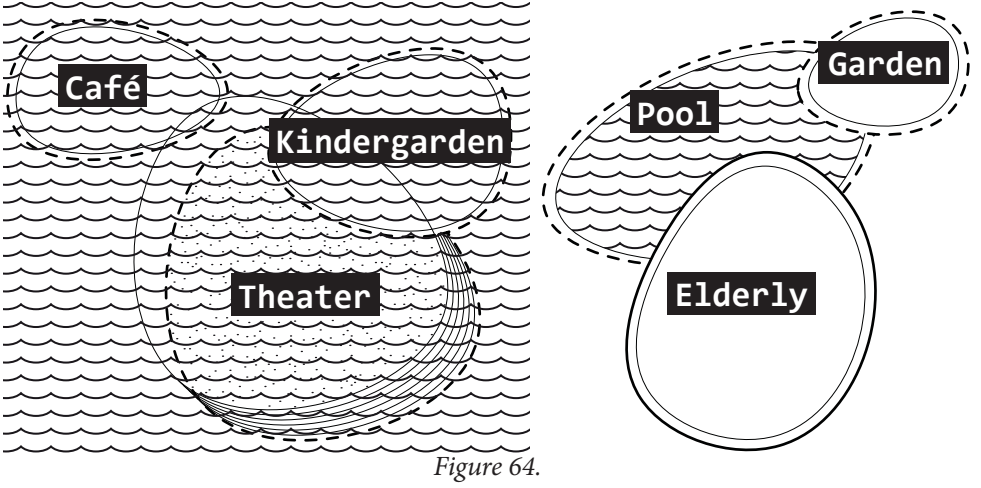

Some spaces profit from the diversity of uses to change vocation over time and make the most out of the infrastructure. How can a school turn into a sports stadium? This proposal relates entirely on spatial organization to create a space that can easily change vocation over the course of the day and/or week. Organized around a courtyard, the classrooms, designed as graded open spaces (audience space), are separated from the sportfield with a movable screen. 


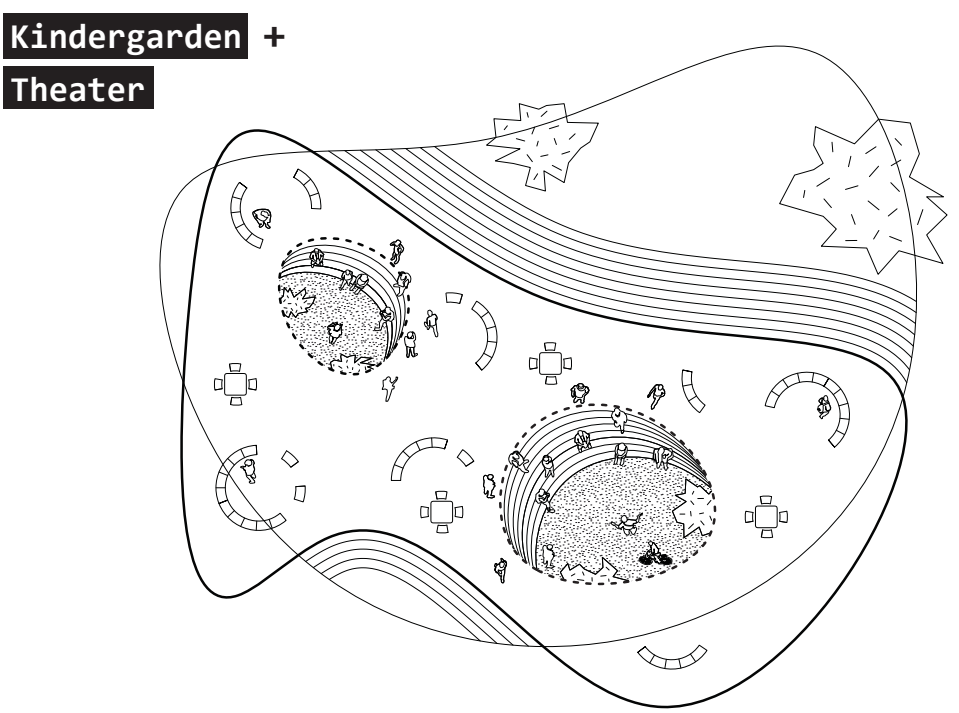

Figure 65.

Pool +

Elderly housing + Garden

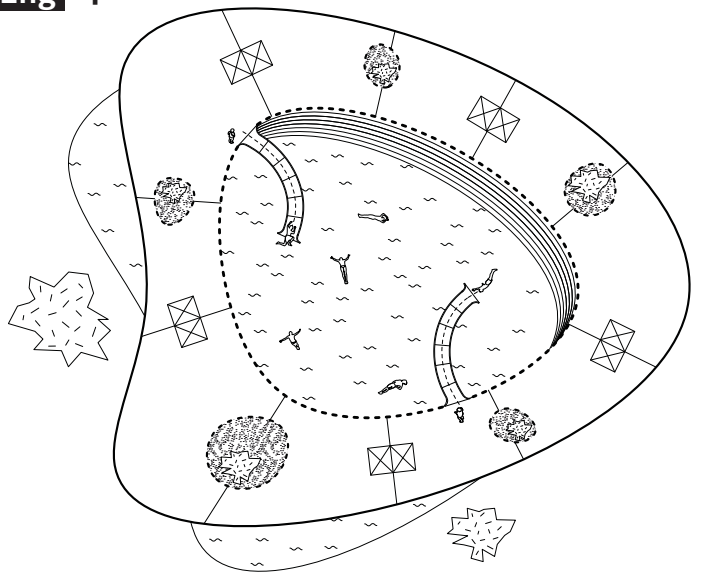

Figure 66.

\section{Sports field +} School

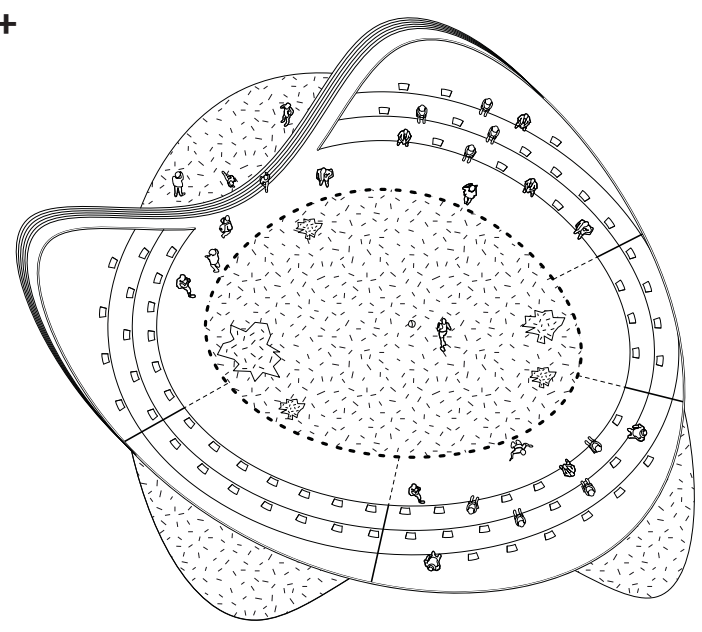

Figure 67. 


\section{Reinforce the sense of community through social confrontations.}
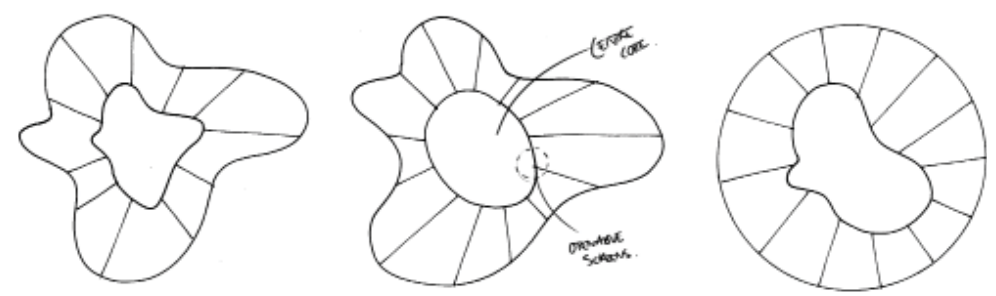

Figure 68.

Various combinations of social and age classes are meant to reinforce the collaboration and diversity within the project. Rounded shapes are favoured for spatial organizations such as to enhance the sense of community between occupants and inhabitants.

\section{Condition \#8:}

\section{Integrate recreation as a social mechanism.}

Playgrounds, parks and gardens are spread throughout the whole project. These spaces for recreation are points of intensity that encourage the presence of people maintaining a constant animation. The insertion of jogging tracks and bike paths through throughout the project creates a new speed and movement allowing it to maintain a certain degree of liveliness. These paths can be seen as activators as they give strength to weaker programs. 
Encourage the combination of horizontality and verticality.

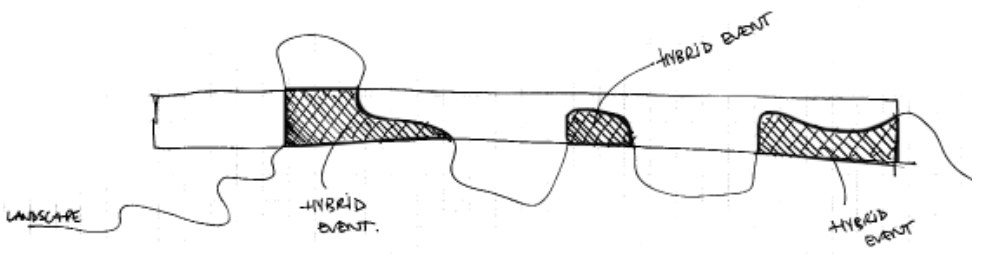

Figure 69.

Urban sponge fuses land and city in a vast infrastructure sprawling across the landscape. While avoiding tall elements, the project hovers over the site as an elongated perforated blanket. The infrastructure remains close to the ground, where diversity and intensity is at its highest degree. Rather than materializing itself through physical architectural elements, verticality here is expressed through the voids designed as open-air theaters connecting the surface of the ground to the roof's surface.

Where Urban sponge meets the train track and the overpass, it gently rises up as a wave. Once it reaches the other side it stretches again to connect with the city's floor. Several holes in the infrastructure allow the train track to be revealed to the sky and thus enhance the project's permeability with the environment.

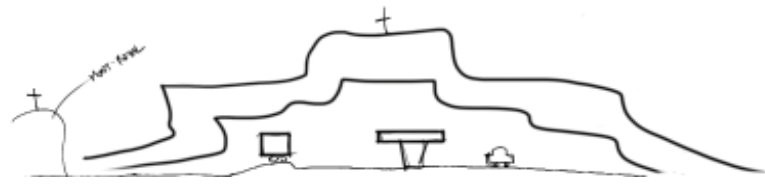

Figure 70. 
Aim for complex, diversified, interrelated and dynamic associations.
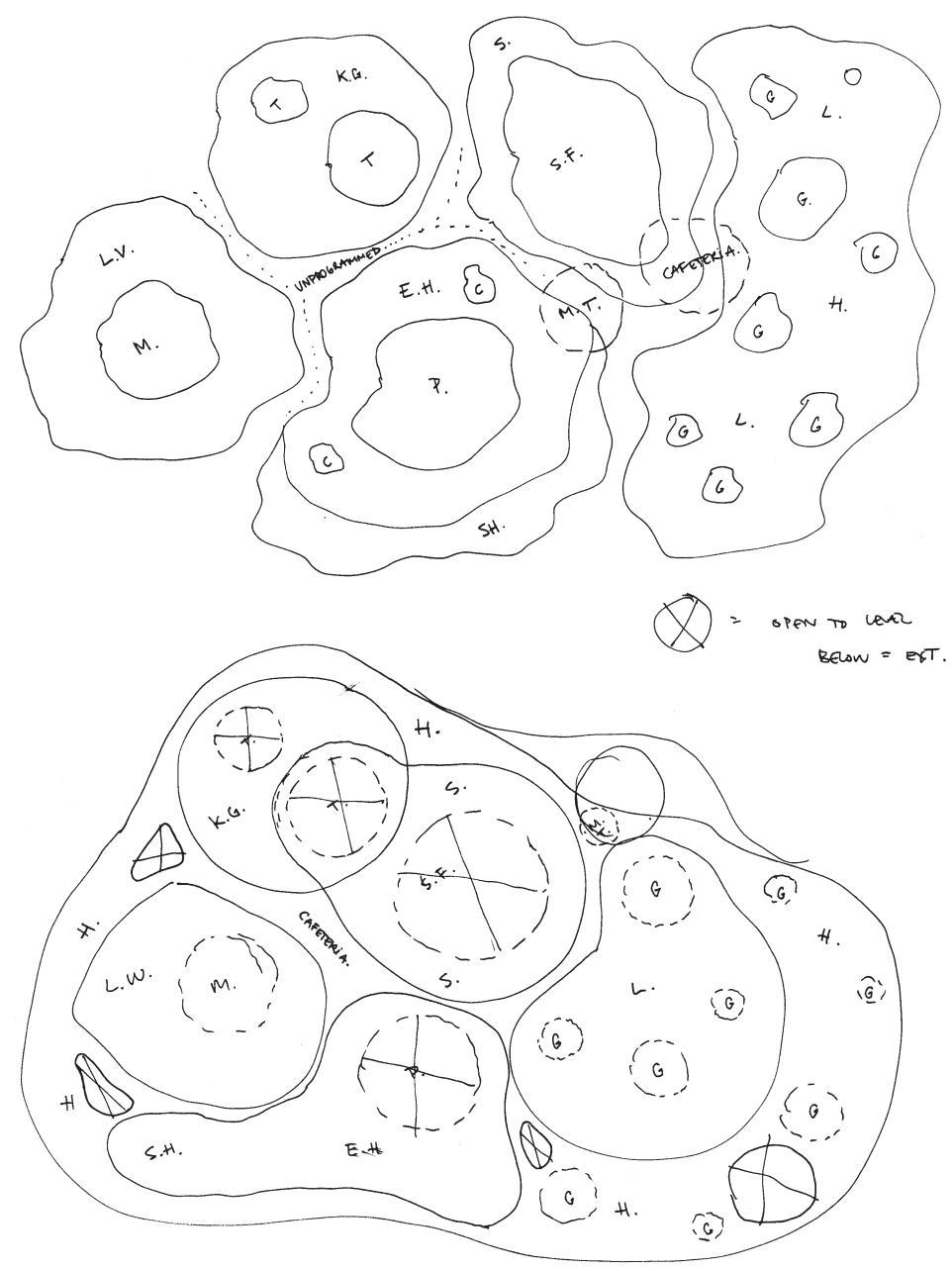

Figure 71.

Acting as a social condenser and incubator for the rebirth of this area of Montreal, Urban sponge relates on variety and complexity to create dialogues between its parts as well as with the immediate environment. As a microcity, it favours dialectics and heterogeneity over unity and homogeneity. Using complex system of programmatic combinations, Urban sponge enables unexpected synergies between private and public realms to allow for the rebirth of the site and reconnect Little Italy to Mile-end. 


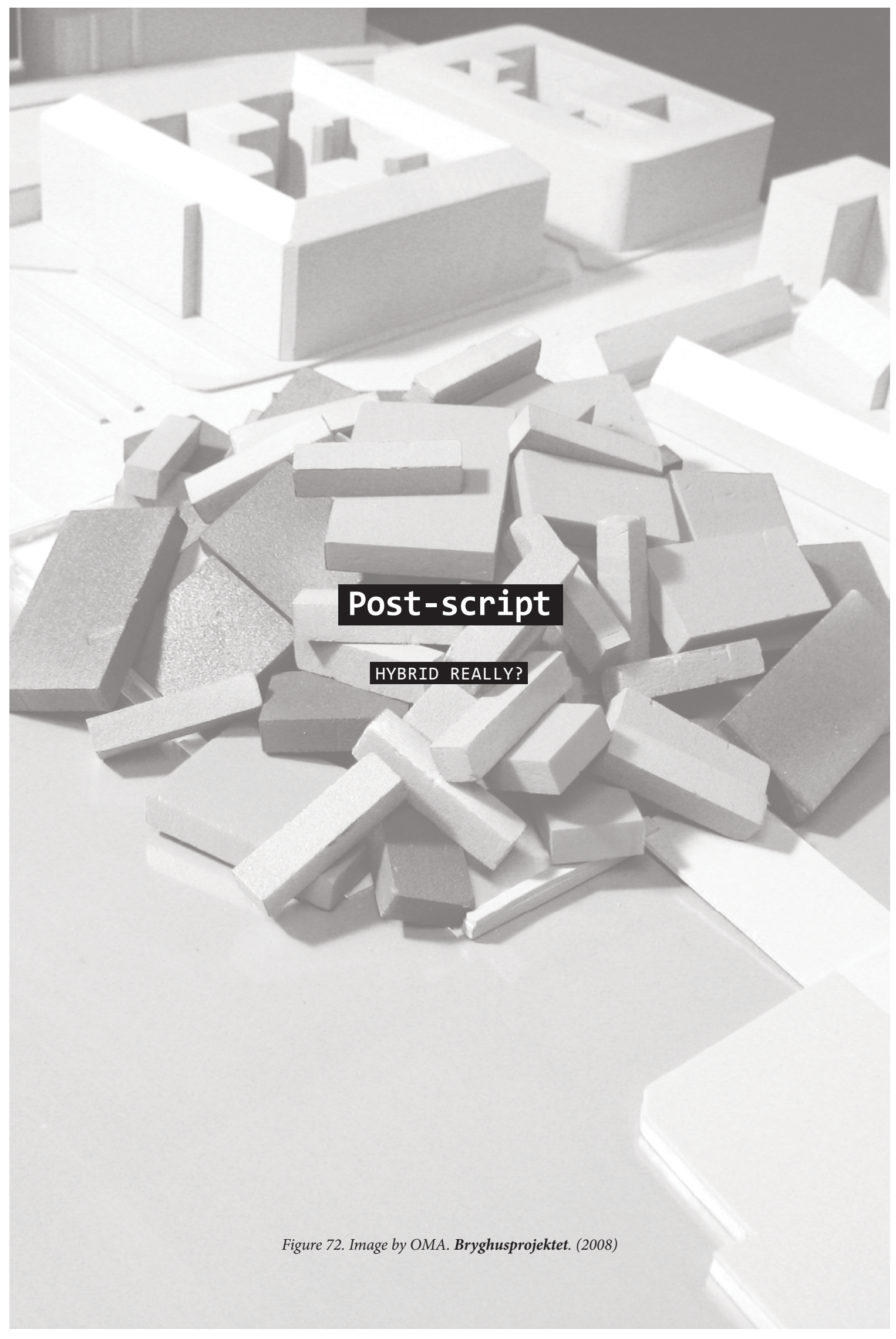




\section{Hybrid Really?}

POST-SCRIPT

While some would say Modernism ended in a wall, we quite don't know yet where hybridity resides. The moment we start defining it, we inevitably undermine hybridity. Because functions have to eventually be assigned to specific spaces, everything, and by everything we mean everything related to architecture will eventually be separated from the whole. Combined functions do not create hybrid situations. To be hybrid, architecture has to make things happen simultaneously.

Hybridity then is something imperceptible. We can, and this thesis has attempted to show it, assign conditions that tend to lean towards hybrid architecture. However hybridity is definitely not something physical nor is it something abstract as it deals with the built environment. This thesis may favor hybridity but has it allowed it to emerge?

It seems that hybridity is a privacy issues. Moreover it might be cultural. Because we define things with boundaries and because some functions require without any doubt these boundaries, hybridity may swing between and rely entirely on private and public issues. The entire building cannot be hybrid but hybrid events can occur within its envelope. For instance, where private and public meet, that can potentially be considered a hybrid event. Hybridity then seems to reside in specific moments within the whole project. 
Finally, hybrid architecture seems to be a strategy rather than a building per se. The hybrid building is not what it claims to be. It doesn't seem to deliver a complete final solution; rather it provides a framework which tends to create hybrid events. But can we state that programs which are separated physically but that do share a relation on an idea level will produce hybrid architecture?

If we consider again the hybrid vehicle, with its two separate engines working independently from one another, they do relate to each other to achieve the same goal. Can we call this hybrid?

Can architectural programs sharing the same space while keeping their original identity, sharing strength to enhance diversity, intensity and density, be considered hybrids? Or can we state that hybrid architecture is something exclusively dedicated to strategic purposes that will by no means generate so-called hybrid buildings?

Hybrid architecture is dead.

Hybridity is a strategy rather than a building.

The hybrid building cannot be what it claims to be.

To succeed, it need not deliver a complete and final solution.

Instead, it is a provocation framework to create

contemporary hybrid events. 


\section{Endnotes}

Angus Stevenson. Oxford Dictionary of English. Oxford University Press. (2010) p. 43

Peter Mark Roget. Roget's Thesaurus of Synonyms and Antonyms. Roydon Reprint Edition. (1987) p.16

Angus Stevenson. Oxford Dictionary of English. Online: http:// www.oxforddictionaries.com/definition/english/blend

Angus Stevenson. Oxford Dictionary of English. Online: http:// www.oxforddictionaries.com/definition/english/blend

Raymond Williams. Keywords, a vocabulary of culture and society. Oxford University Press. (1985). p 66

Bernard Tschumi. Event-cities (praxis). The MIT Press. (1994) p. 155

Stefano Corbo. From Formalism to Weak Form: The Architecture and Philosophy of Peter Eisenman. Ashgate Publishing Limited. (2014) p. 121

Angus Stevenson. Oxford Dictionary of English. Online: http:// www.oxforddictionaries.com/definition/english/fragmentation Angus Stevenson. Oxford Dictionary of English. Online: http:// www.oxforddictionaries.com/definition/english/hybrid

Britannica dictionary. Hybrid (genetics). Online: http://www. britannica.com/science/hybrid

Science Daily. Reference terms: Hybrid. Online: http://www. sciencedaily.com/terms/hybrid.htm

12 Stuart Sim, Borin Van Loon and Richard Appignanesi. Introducing Critical Theory. Totem Books. (2001) p. 170

Rem Koolhaas. Hyperbuilding. (1996). Online: http://oma.eu/ projects/hyperbuilding www.oxforddictionaries.com/definition/english/interaction 
Bernard Tschumi. Event-cities (praxis). The MIT Press. (1994) p. 299

Angus Stevenson. Oxford Dictionary of English. Oxford University Press. (2010)

Bernard Tschumi. Event-cities (praxis). The MIT Press. (1994) p. 299

Bernard Tschumi. Event-cities (praxis). The MIT Press. (1994) p. 13

Alan Bullock \& Stephen Trombley. The New Fontana Dictionary of Modern Thought. Harper Collins publishers. (1999) p. 854

Angus Stevenson. Oxford Dictionary of English. Oxford University Press. (2010)

Bernard Tschumi . Event-cities (praxis). The MIT Press. (1994) p. 329

Alan Bullock \& Stephen Trombley. The New Fontana Dictionary of Modern Thought. Harper Collins publishers. (1999) p. 507

Alan Bullock \& Stephen Trombley. The New Fontana Dictionary of Modern Thought. Harper Collins publishers. (1999) p. 664

Aurora Fernández Per, Javier Mozas and Javier Arpa. This is hybrid: An analysis of mixed-used buildings. Spain: $\mathrm{a}+\mathrm{t}$ Density series. (2014) p. 14

Bernard Tschumi was one of the first architect to propose a theory about hybrid architecture. He truly believed in architecture as a container of events and/or actions. He approached hybrid architecture through theories such as trans-programming, disprogramming and cross-programming. magazine. (2015) p. 51 

magazine. (2015) p. 51

Peter Block. The Essentials Issue: A Sense of Belonging. Kinfolk magazine. (2015) p. 51

Aurora Fernández Per, Javier Mozas and Javier Arpa. This is hybrid: An analysis of mixed-used buildings. Spain: $\mathrm{a}+\mathrm{t}$ Density series. (2014) p. 12 Buildings. Architectural books. (1985) p. 4

Aurora Fernández Per, Javier Mozas and Javier Arpa. This is hybrid: An analysis of mixed-used buildings. Spain: $\mathrm{a}+\mathrm{t}$ Density series. (2014) Back cover

Aurora Fernández Per, Javier Mozas and Javier Arpa. This is hybrid: An analysis of mixed-used buildings. Spain: $\mathrm{a}+\mathrm{t}$ Density series. (2014) Back cover

Jane Jacobs. Hybrid High-rises. Paper presented at Debating the City: City Living and Cosmopolitanism. Museum of Sydney. (1999) p.3

Aurora Fernández Per, Javier Mozas and Javier Arpa. This is hybrid: An analysis of mixed-used buildings. Spain: $\mathrm{a}+\mathrm{t}$ Density series. (2014) p. 26

36 Aurora Fernández Per, Javier Mozas and Javier Arpa. Hybrids II: Low-Rise Mixed-Use Buildings. Hybrids Series. Volume 3. (2008) p. 25

Aurora Fernández Per, Javier Mozas and Javier Arpa. This is hybrid: An analysis of mixed-used buildings. Spain: $\mathrm{a}+\mathrm{t}$ Density series. (2014) Back cover

Bernard Tschumi. Event-cities (praxis). The MIT Press. (1994) p. 157

Rem Koolhaas and Bruce Mau. S,M,L,XL. Monacelli Press. (1995) p. 497 Buildings. Architectural books. (1985) p. 6 
Aurora Fernández Per, Javier Mozas and Javier Arpa. Hybrids I. High-Rise Mixed-Use Buildings. Hybrids Series. Volume 31. (2008) p. 7

Joseph Fenton. Pamphlet Architecture no 11: Hybrid Buildings. Architectural books. (1985) p. 3

Rem Koolhaas. Delirious New York. The Monacelli press. (1997) p. 85

Rem Koolhaas. Delirious New York. The Monacelli press. (1997) p. 89

Rem Koolhaas. Delirious New York. The Monacelli press. (1997) p. 89

Rem Koolhaas and Bruce Mau. $S, M, L, X L$. Monacelli Press. (1995) p. 499

Aurora Fernández Per, Javier Mozas and Javier Arpa. This is hybrid: An analysis of mixed-used buildings. Spain: $\mathrm{a}+\mathrm{t}$ Density series. (2014) p.12

Steven holl. Linked Hybrid. (2009) Online: http://www. stevenholl.com/projects/beijing-linked-hybrid?

Peter Cook. Archigram. Praeger publishers. (1973) p.120 high density. Wordpress online: http://densityarchitecture. wordpress.com/2013/09/28/social-and-architecturalimplications-of-high-density/

Rem Koolhaas. The Hyperbuilding. (1996). Online: http://oma. eu/projects/hyperbuilding

53 Aurora Fernández Per, Javier Mozas and Javier Arpa. This is hybrid: An analysis of mixed-used buildings. Spain: $\mathrm{a}+\mathrm{t}$ Density series. (2014) p. 26

$54 \quad$ Rem Koolhaas and Bruce Mau. S, M,L,XL. Monacelli Press. (1995) p. 504

Aurora Fernández Per, Javier Mozas and Javier Arpa. This is hybrid: An analysis of mixed-used buildings. Spain: $\mathrm{a}+\mathrm{t}$ Density series. (2014) p. 13 

trand Reinhold. (1979) p. 70

Peter Blake. Form Follows Fiasco. Little Brown and Company publishers. (1974) p. 86

Jane Jacobs. Hybrid High-rises. Paper presented at Debating the City: City Living and Cosmopolitanism. Museum of Sydney. (1999) p. 5 and Decline of America's Man-Made Landscape. Simon \& Schuster. (1993) p.79

Peter Blake. Form Follows Fiasco. Little Brown and Company publishers. (1974) p. 13

Peter Blake. Form Follows Fiasco. Little Brown and Company publishers. (1974) p. 13

Jan Gehl. Cities for People. Island press. (2010) p. 26

64 Jane Jacobs. Hybrid High-rises. Paper presented at Debating the City: City Living and Cosmopolitanism. Museum of Sydney. (1999) p. 6

65 Rem Koolhaas and Bruce Mau. S, $M, L, X L$. Monacelli Press. (1995) p. 512

Rem Koolhaas and Bruce Mau. S,M,L,XL. Monacelli Press. (1995) p. 512

Peter Blake. Form Follows Fiasco. Little Brown and Company publishers. (1974) p. 145

Peter Blake. Form Follows Fiasco. Little Brown and Company publishers. (1974) p. 67

Jane Jacobs. The death and life of great American cities. Random house. (1961) p. 161 
71 Baldea, Maja. Qualities of density. Wordpress online: http:// densityarchitecture.wordpress.com/2013/01/27/qualities-ofdensity/

Steward Brand. What Squatter Cities Can Teach Us. TED Talk. (2007)

Aurora Fernández Per, Javier Mozas and Javier Arpa. Hybrids II. Low-Rise Mixed-Use Buildings. Hybrids Series. Volume 32. (2008) p. 5

74 Rudy Uytenhaak, Rudy. Cities full of space: Qualities of density. Nai010 publishers. (2013) p. 74

Baldea, Maja. Density architecture, future adaptive architectures of high density. Wordpress online: https:// densityarchitecture.wordpress.com/2012/12/03/futureadaptive-architectures-of-high-density-2/

Rudy Uytenhaak, Rudy. Cities full of space: Qualities of density. Nai010 publishers. (2013) p. 11

Rudy Uytenhaak, Rudy. Cities full of space: Qualities of density. Nai010 publishers. (2013) p. 12

Baldea, Maja. Qualities of density. Wordpress online: http:// densityarchitecture.wordpress.com/2013/01/27/qualities-ofdensity/

79 Baldea, Maja. Qualities of density. Wordpress online: http:// densityarchitecture.wordpress.com/2013/01/27/qualities-ofdensity/

Aurora Fernández Per, Javier Mozas, Javier Arpa. Why Density Matters? Debunking the myth of the cubic watermelon. Spain: a+t Density series. (2014) p. 10

81 Aurora Fernández Per, Javier Mozas, Javier Arpa. Why Density Matters? Debunking the myth of the cubic watermelon. Spain: $a+t$ Density series. (2014) p. 10

Rudy Uytenhaak, Rudy. Cities full of space: Qualities of density. Nai010 publishers. (2013) p. 74

Rudy Uytenhaak, Rudy. Cities full of space: Qualities of density. Nai010 publishers. (2013) p. 10 
Aurora Fernández Per, Javier Mozas, Javier Arpa. Hybrids I. High-Rise Mixed-Use Buildings. Hybrids Series. Volume 31. (2008) p. 3

Aurora Fernández Per, Javier Mozas, Javier Arpa. Hybrids I. High-Rise Mixed-Use Buildings. Hybrids Series. Volume 31. (2008) p. 3

Aurora Fernández Per, Javier Mozas, Javier Arpa. This is hybrid: An analysis of mixed-used buildings. Spain: $\mathrm{a}+\mathrm{t}$ Density series. (2014) p. 41

Aurora Fernández Per, Javier Mozas, Javier Arpa. Why Density Matters? Debunking the myth of the cubic watermelon. Spain: $a+t$ Density series. (2014) p. 12

Baldea, Maja. Qualities of density. Wordpress online: http:// densityarchitecture.wordpress.com/2013/01/27/qualities-ofdensity/

Jan Gehl. Cities for People. Island press. (2010) p. 69

Jan Gehl. Cities for People. Island press. (2010) p. 69

Aurora Fernández Per, Javier Mozas, Javier Arpa. This is hybrid: An analysis of mixed-used buildings. Spain: $\mathrm{a}+\mathrm{t}$ Density series. (2014) p. 16

Rudy Uytenhaak, Rudy. Cities full of space: Qualities of density. Nai010 publishers. (2013) p. 11

Jaime Lerner. Urban Acupuncture. Island Press. (2014) p. 25

$94 \quad$ Jane Jacobs. The death and life of great American cities. Random house. (1961) p. 161

95 Jane Jacobs. The death and life of great American cities. Random house. (1961) p. 163 Jane Jacobs. The death and life of great American cities. Random house. (1961) p. 162

97 Jan Gehl. Cities for People. Island press. (2010) p. 69

98 Bernard Tschumi. Event-cities (praxis). MIT Press. (1994). P.409 


\section{List of figures}

Figure 1. Blending. Drawing by Valérie Derome-Massé. (2015)

Figure 2. Community. Drawing by Valérie Derome-Massé. (2015)

Figure 3. Fragmentation. Drawing by Valérie Derome-Massé. (2015)

Figure 4. Hyperbuilding. Drawing by Valérie Derome-Massé. (2015)

Figure 5. Mutation. Drawing by Valérie Derome-Massé. (2015)

Figure 6. Segregation. Drawing by Valérie Derome-Massé. (2015)

Figure 7. Photograph and project by Steven Holl Architects. Linked Hybrid. (2003)

Figure 8. Dino-shark. Drawing by Valérie Derome-Massé. (2015)

Figure 9. Photograph of Arrowhead Lakes, Arizona by Justin Fantl. Kinfolk 18. (2015)

Figure 10. Photograph of Arrowhead Lakes, Arizona by Justin Fantl. Kinfolk 18. (2015)

Figure 11. Photograph by Steven Holl Architects. Vanke Center. (2006)

Figure 12. Photograph by Steven Holl Architects. Vanke Center. (2006)

Figure 13. Image by Steven Holl Architects. Vanke Center. (2006)

Figure 14. Drawing by Joseph Fenton. Pamphlet Architecture: Hybrid Buildings. Architectural Books.(1985)

Figure 15. Model by Yona Friedman. Ville Spatiale. (1959)

Figure 16. Drawing by Yona Friedman. Ville Spatiale. (1959)

Figure 17. Drawing by Yona Friedman. Shanghai Bridge. (2009)

Figure 18. Drawing by Bernard Tschumi. Project Bridge-City, Lausanne. (1988)

Figure 19. Drawing and model by Yona Friedman. Shanghai Bridge Project. (2009) 
Figure 20. Image by Ja Architecture Studio Inc. Solar Park South. Online: jastudioinc.com

Figure 21. Drawing by Rem Koolhaas. Delirious New York. The Monacelli Press. (1997)

Figure 22. Image by OMA. Dubai Renaissance. (2006)

Figure 23. Image by OMA. Dubai Renaissance. (2006)

Figure 24. Photograph and project by Steven Holl Architects. Linked Hybrid. (2003)

Figure 25. Image from Museum of Modern Art, New York. Project by Steven Holl. Linked Hybrid. (2003)

Figure 26. Image from Museum of Modern Art, New York. Project by Steven Holl. Linked Hybrid. (2003)

Figure 27. Photograph from Archigram Archives. Archigram Group. Online: archigram.westminster.ac.uk/about.

Figure 28. Drawing by Peter Cook. Project Mound. (1964)

Figure 29. Image by OMA. Hyperbuilding. (1996)

Figure 30. Image by OMA. Hyperbuilding. (1996)

Figure $31 . \quad$ Drawing by Yona Friedman. Ville Spatiale. (1959)

Figure 32. D D D D Derawing by Pal Steinberg, The New Magine. (1976)

Figure 33. Drawing by Le Corbusier. Radiant City. (1924)

Figure 34. Drawing by Le Corbusier. Radiant City. (1924)

Figure 35. Model by Le Corbusier. Radiant City. (1924)

Figure 36. Drawing by Le Corbusier. Radiant City. (1924)

Figure 37. Image by Rem Koolhaas. Delirious New York. The Monacelli Press. (1997)

Figure 38. Image by Rem Koolhaas. Delirious New York. The Monacelli Press. (1997)

Figure 39. Image by OMA. Bryghusprojektet. (2008) 
Figure 40. Photograph by Christoph Gielen. Decoding the hidden circles of suburbia. (2014)

Figure 41. Photograph by Christoph Gielen. Decoding the hidden circles of suburbia. (2014)

Figure 42. Image by UNstudio. Mobius House. (1993)

Figure 43. Image by UNstudio. Mobius House. (1993)

Figure 44. Image by Clive Wilkinson Architects. Endless Workspace. (2015) Online: www.designboom.com/design/clive-wilkinsonarchitects-endless-workplace-london-12-03-2015/

Figure 45. Image by Clive Wilkinson Architects. Endless Workspace. (2015) Online: www.designboom.com/design/clive-wilkinsonarchitects-endless-workplace-london-12-03-2015/

Figure 46. Time-study. Image by Valérie Derome-Massé. (2015)

Figure 47. Time-study. Image by Valérie Derome-Massé. (2015)

Figure 48. Time-study. Image by Valérie Derome-Massé. (2015)

Figure 49. Time-study. Image by Valérie Derome-Massé. (2015)

Figure 50. Time-study. Image by Valérie Derome-Massé. (2015)

Figure 51. Drawing by Valérie Derome-Massé. (2015)

Figure 52. Image by Sou Fujimoto Architects. Energy Forest. (2013)

Figure 53. Image by Sou Fujimoto Architects. Energy Forest. (2013)

Figure 54. Time-study. Image by Valérie Derome-Massé. (2015)

Figure 55. Photograph by Shawn Knol. Flickr online: https://www.flickr. $\mathrm{com} / \mathrm{photos} / \mathrm{knol} /$

Figure 56. Photograph by Alexi Kostibas. Flickr online: https://www.flickr. com/photos/alexik/103512941

Figure 57. Encourage the revitalisation and/or bring back to life a certain urban area. Drawing by Valérie Derome-Massé. (2015)

Figure 58. Create links between parts of the city allowing it to act as an urban generator. Drawing by Valérie Derome-Massé. (2015) 
Figure 59.

Figure 60.

Figure 61.

Figure 62.

Figure 63.

Figure 64.

Figure 65.

Figure 66.

Figure 67.

Figure 68.

Figure 69.

Figure 70.

Figure 71.

Figure 72.
Create links between parts of the city allowing it to act as an urban generator. Drawing by Valérie Derome-Massé. (2015)

Form a mutation between landscape and architecture.

Drawing by Valérie Derome-Massé. (2015)

Form a mutation between landscape and architecture.

Drawing by Valérie Derome-Massé. (2015)

Create intense environments of cross fertilization. Drawing by Valérie Derome-Massé. (2015)

Share intensities between programs. Drawing by Valérie Derome-Massé. (2015)

Encourage full-time buildings rather than part-time buildings (intensity of usage). Drawing by Valérie Derome-Massé. (2015)

Encourage full-time buildings rather than part-time buildings (intensity of usage). Drawing by Valérie Derome-Massé. (2015)

Encourage full-time buildings rather than part-time buildings (intensity of usage). Drawing by Valérie Derome-Massé. (2015)

Encourage full-time buildings rather than part-time buildings (intensity of usage). Drawing by Valérie Derome-Massé. (2015)

Reinforce the sense of community through social confrontations. Drawing by Valérie Derome-Massé. (2015)

Encourage the combination of horizontality and verticality. Drawing by Valérie Derome-Massé. (2015)

Encourage the combination of horizontality and verticality. Drawing by Valérie Derome-Massé. (2015)

Aim for complex, diversified, interrelated and dynamic associations. Drawing by Valérie Derome-Massé. (2015)

Image by OMA. Bryghusprojektet. (2008) 


\section{Bibliography}

Peter Mark Roget. Roget's Thesaurus of Synonyms and Antonyms. Roydon Reprint Edition. (1987)

Angus Stevenson. Oxford Dictionary of English. Oxford University Press. (2010)

Raymond Williams. Keywords, a vocabulary of culture and society. Oxford University Press. (1985)

Alan Bullock \& Stephen Trombley. The New Fontana Dictionary of Modern Thought. Harper Collins publishers. (1999)

Stefano Corbo. From Formalism to Weak Form: The Architecture and Philosophy of Peter Eisenman. Ashgate Publishing Limited. (2014)

Britannica dictionary. Hybrid (genetics). Online: http://www. britannica.com/science/hybrid

Science Daily. Reference terms: Hybrid. Online: http://www. sciencedaily.com/terms/hybrid.htm

Aurora Fernández Per, Javier Mozas and Javier Arpa. Why Density Matters? Debunking the myth of the cubic watermelon. Density series. (2014)

Baldea, Maja. Qualities of density. Wordpress online: http:// densityarchitecture.wordpress.com/2013/01/27/qualities-ofdensity/

Baldea, Maja. Social and architectural Implications of high density. Wordpress online: http://densityarchitecture. wordpress.com/2013/09/28/social-and-architecturalimplications-of-high-density/

Baldea, Maja. Understanding density. Wordpress online: http:// densityarchitecture.wordpress.com/2013/01/18/understandingdensity/

Rudy Uytenhaak, Rudy. Cities full of space: Qualities of density. Nai010 publishers. (2013) 
Gary Hustwit. Urbanized. Documentary, Format DVD, Duration: 1:54:25. (2011)

Steward Brand. What Squatter Cities Can Teach Us. TED Talk. (2007)

Linked Hybrid / Steven Holl Architects. ArchDaily online: http://www.archdaily.com/34302/linked-hybrid-steven-hollarchitects/

Aurora Fernández Per, Javier Mozas and Javier Arpa. This is hybrid: An analysis of mixed-used buildings. Density series. (2014)

Aurora Fernández Per, Javier Mozas and Javier Arpa. Hybrids I. High-Rise Mixed-Use Buildings. Hybrids Series. Volume 31. (2008).

Aurora Fernández Per, Javier Mozas and Javier Arpa. Hybrids II. Low-Rise Mixed-Use Buildings. Hybrids Series. Volume 32. (2008).

Aurora Fernández Per, Javier Mozas and Javier Arpa. Hybrids III. Residential Mixed-Use Buildings. Hybrids Series. Volume 33-34. (2009)

Aurora Fernández Per, Javier Mozas and Javier Arpa. Housing and flexibility I. Housing and flexibility Series. Volume 12. (1998)

BIG's combined power plant and ski slope is turning science fiction into fact. Dezeen magazine online: http://www.dezeen. com/2014/07/12/movie-interview-bjarke-ingels-big-amagerbakke-power-plant-ski-slope/

Rosenfield, Karissa. Bjarke Ingels on Promiscuous Hybrids and Worldcraft. (10 Sep 2014). ArchDaily online http://www. archdaily.com/?p=546867

Hybrid Architecture blog. Book review: Pamphlet Architecture, Hybrid Buildings. Online: http://hybridarchitecture.tumblr. com/post/11913529085/book-review-pamphlet-architecturehybrid

Joseph Fenton. Pamphlet Architecture no 11: Hybrid Buildings. Architectural books. (1985) 
Andrea Branzi. No stop city. Archizoom Association. (1969)

Peter Cook. Archigram. Praeger publishers. (1973)

Larry Busbea. Topologies: The Urban Utopia in France 19601970. Massachussets Institute of Technology. (2007)

Rem Koolhaas. Delirious New York. The Monacelli press. (1997)

Rem Koolhaas and Bruce Mau. S,M,L,XL. Monacelli Press. (1995)

Bernard Tschumi. Event-cities (praxis). The MIT Press. (1994)

Bernard Tschumi. Event-cities 2. The MIT Press. (2000)

Jones, Rennie. The 12 Latest Trends in Affordable Housing. Architizer online http://architizer.com/blog/latest-trends-inaffordable-housing/

Bartolacci, James. 10 Innovative Affordable Housing Designs For Sustainable Living. Architizer online http://architizer.com/ blog/affordable-housing/

Baldea, Maja. Formal typologies of dense residential architectures. Wordpress online http://densityarchitecture. wordpress.com/2013/01/21/formal-typologies-of-denseresidential-architectures/

Aurora Fernández Per, Javier Mozas and Javier Arpa. Housing and flexibility I. A+t architecture publishers. (1998)

Aurora Fernández Per, Javier Mozas and Javier Arpa. Density: New Collective Housing. A $+\mathrm{t}$ architecture publishers. (2006)

Peter Blake. Form Follows Fiasco. Little Brown and Company publishers. (1974)

Alberto Ulisse. Energy city: an experimental process of new energy scenarios. Babel publishers. (2011)

Andy van den Dobbelsteen. Enabling Urban Resilience. Duration: 15:44min. TED Talk. (2012) 
Peter Block. The Essentials Issue: A Sense of Belonging. Kinfolk magazine. (2015)

Robert Venturi. Complexity and Contradiction in Architecture. The Museum of Modern Art. (1977)

Jane Jacobs. Hybrid High-rises. Paper presented at Debating the City: City Living and Cosmopolitanism. Museum of Sydney. (1999)

Leonie Sandercock. Towards Cosmopolis: Planning for Multicultural Cities. Wiley. (1997)

Martin Van Schaik and Otakar Macel. Exit Utopia: Architectural Provocations. 1956-76. Prestel. (2005)

Simon Sadler. Archigram: Architecture Without Architecture. MIT Press. (2005)

Brent C. Brolin. The Failure of Modern Architecture. Van Nostrand Reinhold. (1979)

Hubert-Jan Henket and Hilde Heynen. Back from Utopia: The Challenge of the Modern Movement. 010 Publishers. (2002)

Michael Booth. The Almost Nearly Perfect People: The Truth about the Nordic Miracle. Vintage Books London. (2014)

Avi Friedman. Room for Thought: Rethinking Home and Community Design. Penguin Canada. (2005)

Robert Bruegmann. Sprawl: A Compact History. The University of Chicago Press. (1992)

Nathan Heller. Northern Lights: Do the Scandinavians really have it all figured out? The New Yorker magazine. (February $16,2015)$

Michael Booth. Dark lands: the grim truth behind the Scandinavian miracle. The guardian. (January 27, 2014)

Brent C. Brolin. Architecture in context: fitting new buildings with old. Van Nostrand Reinhold. (1980)

Yona Friedman. Utopie Réalisable. Publications L'éclat. (2005)

Yona Friedman. Pro domo. Barcelona Actar. (2006) 
Kevin Lynch. The Image of the City. MIT Press. (1960)

James Howard Kunstler. The Geography of Nowhere: The Rise and Decline of America's Man-Made Landscape. Simon \& Schuster. (1993)

Walter Gropius. The new architecture and the Bauhaus. The MIT Press. (1965)

Le Corbusier. Towards a New Architecture. Martino Publishing. Translated from the original 1927 edition. (2014)

Le Corbusier \& Pierre Jeanneret. Architecture d'aujourd'hui. Numéro 10. (May 1992)

Jaime Lerner. Urban Acupuncture. Island Press. (2014)

Steven Holl. Linked Hybrid. (2009). Online http://www. stevenholl.com/project-detail.php?id=58 